\title{
Droplet size and velocity characteristics of water-air impinging jet atomizer
}

\author{
Y Xia, L Khezzar, M Alshehhi \& Y Hardalupas(*) \\ Mechanical Engineering Department, Petroleum Institute, Abu Dhabi, UAE \\ (*) Mechanical Engineering Department, Imperial College, London
}

\begin{abstract}
A water-air impinging jets atomizer is investigated in this study, which consists of flow visualization using high speed photography and mean droplet size and velocity distribution measurements of the spray using Phase Doppler Anemometry (PDA). Topological structures and break up details of the generated spray in the far and near fields are presented with and without air jet and for an impinging angle of $90^{\circ}$. Spray angle increases with the water jet velocity, air flow rate and impinging angle. PDA results indicate that droplet size is smallest in the spray center, with minimum value of Sauter mean diameter (SMD) of $50 \mu \mathrm{m}$ at the air flow rate of $\mathrm{Q}_{\mathrm{m}}=13.50 \mathrm{~g} / \mathrm{min}$. SMD of droplets increases towards the spray outer region gradually to about $120 \mu \mathrm{m}$. The mean droplet velocity component $\mathrm{W}$ along the air-jet axis is highest in the spray center and decreases gradually with increasing distance from the spray center. SMD normalized by the air nozzle diameter is found firstly to decrease with gas-to-liquid mass ratio (GLR) and air-to-liquid momentum ratio (ALMR) and then remain almost constant. Its increasing with aerodynamic Weber number indicates an exponential variation. The study sheds light on the performance of water-air impinging jets atomizers providing useful information for future CFD simulation works.
\end{abstract}

Keywords: Impinging Jets, Atomization, PDA, Droplet Size and Velocity. 


\section{Introduction}

Liquid atomizers are relevant to a number of practical applications such as combustors of propulsion systems and humidification systems and usually involve complex air liquid two-phase flow behavior (Lefebvre 1988). Previous studies focused on the effects of different configurations. Twin fluid atomization in which the gas kinetic energy is used to assist liquid jet fragmentation is probably the most widely used and a generic widely studied form is liquid jets in coaxial air streams (Chigier and Farago 1992; Hardalupas and Whitelaw 1996 ; Engelbert et al.1995; Lasheras et al.1998) or a liquid sheet between two air sheets (Mansour and Chigier 1990), or internal mixing atomizers as studied by Zaremba et al. (2017).

Another configuration involves twin impinging liquid jets which form a liquid sheet that disintegrates into ligaments and droplets (Ashgriz 2011; Dombrowksi and Hopper 1964; Li and Ashgriz 2006; Vassalo et al. 1992). While twin fluid atomization displays advantages in simplicity of design, it leads to good atomization only at high injection liquid velocities, which of course limits the operating conditions. A variant of the twin-liquid jet atomizer, which combines the liquid impinging jets and air-assisted atomization and is less prone to operating limitations, is formed by adding an additional air jet, which impinges on the two twin liquid jets (Avulapati and Venkata 2013, Inoue et al. 2013). Such configuration can be found in propellant liquid rocket engines (Sutton and Ross 1976) and various chemical reaction processes with advantages of simple fabrication and satisfactory mixing performance over other internal mixing atomizers (Ibrahim and Przekwas 1991; Lefebvre 1988; Sutton 1986). A sub-variant of this configuration, that uses one single liquid jet impinging on another gas jet, has been successfully used in the internal geometry of F-jet type atomisers, which are used to atomize heavy fuel oil and emulsions in burners for furnaces, leading to lower $\mathrm{NO}_{\mathrm{x}}$ emissions and higher combustion efficiency (Boden et al. 1999). The resulting two-phase flow from the interaction of the two liquid impinging jets with a third additional impinging jet is a highly complex one. The present experimental work provides additional information on the near-field interaction of two twin liquid jets and one air jet on the droplet sizes and behavior downstream of the impingement point in such systems. 
Understanding the mechanism of liquid jet disintegration is crucial to the design or optimization in performance for such systems. The interaction of the air stream with liquid stream is a major influencing factor in the subsequent behavior of the generated spray. Thus, it has been recognized that atomization in such systems takes place in two stages, in the near field an initial or primary break up dominated by surface tension and a secondary one where a small liquid sheet and large droplets are broken down into a population of small droplets by viscous forces generated in the mean and turbulent motions of the turbulent air spray, see Lasheras et al. (1998) and Varga et al. (2003). For co-axial jet, the primary break up involves jet disintegration via membrane type (Farago and Chigier 1992) and/or annular sheets inclined at an angle to the flow before disintegration. The findings on the breakup processes in the near field of the liquid medium have been the result of flow visualization using fast photography.

In previous atomization studies, droplet size data in the form of Sauter mean diameter (SMD or $D_{32}$ ) was correlated to the gas velocity elevated to a negative power. Sauter mean diameter is defined as a mean diameter of a spherical particle or droplet that has the same volume to surface area ratio with the droplets of interest. While such correlations are useful for practical design, they remain crude and specific to the experimental conditions on which they were based. On the other hand and to the present day, the accurate prediction of the variation of droplets diameters and their spatial distribution as a function of system geometry and injection conditions remains elusive (Varga et al. 2003).

In order to understand the mechanism of impinging jets atomization (without an air jet) and improve the performance of atomizers, a number of studies have been conducted to investigate the spray patterns, liquid sheet breakup length, liquid sheet velocity characteristics, thickness of liquid sheet, size and velocity of droplets generated (Zaremba et al. 2017; Dombrowksi and Hopper 1964; Li and Ashgriz 2006; Choo \& Kang 2007; Bush and Husha 2004; Jung et al. 2010; and $\mathrm{Ma}$ et al. 2015). From the various studies conducted, it is now clear that the liquid jet velocity or liquid flow rate has a major influence on the droplet sizes and a large variation of mean droplet sizes have been measured that extend from $40 \mu \mathrm{m}$ (Indiana et al. 2015) to as high as $300 \mu \mathrm{m}$ (Shen et al. 1997). In terms of numerical work, the Direct Numerical Simulation of Chen et al. (2013) are worthy of note where the prediction of flow details using an improved volume-of-fluid (VOF) algorithm, which is augmented with adaptive mesh refinement 
techniques, had shown that the details of the flow are very sensitive to the mesh resolution. Inoue et al. (2015) developed an Eulerian-Lagrangian hybrid method for the twin-liquid jet atomizer with good concordance between numerical and experimental mass flux distributions.

While the configuration with two impinging liquid jets has received relatively non-negligible attention on both theoretical and experimental fronts, the configuration with an additional air jet received comparatively less attention. To the authors' knowledge, one work that considered such a configuration is that of Mohan et al. (2012) and Avulapati and Venkata (2013), who studied the atomization performance of an external mixing air-assisted impinging atomizer, which consisted of two water jets and one air jet. The study used CCD camera in the backlit direct imaging mode and Particle/Droplet Imaging Analysis (PDIA) method (Avulapati and Venkata 2013) to characterize the resulting spray. Using different fluids they were able to demonstrate that beyond a critical gas to liquid ratio (GLR) of 0.05 the liquid properties do not affect atomization significantly and that the angle of impingement has minor influence on the subsequent droplet sizes. They also found that the effect of impingement angle on the spray angle is higher at higher liquid velocity and that higher viscosity liquids exhibit lower spray angles. The flow visualization pictures revealed that the air jet interacts with the two liquid jets and eliminates the liquid sheet formation. The details of the break up mode in the vicinity of the impingement point have not been described since the photographs were taken from a large distance. Additional research on the configuration studied by Avulapati and Venkata (2013) was carried out by Inoue et al. (2013). Atomization of liquid-air-liquid impinging jets was recorded using a high speed camera for visualization and a combination of CCD camera and pulsed YAG laser was utilized for droplet size measurement. They showed that with only an air mass flow of $1 \%$ of the liquid jets mass flow rate atomization is remarkably enhanced. The flow visualization results provided some description of the primary atomization region, such as burst of the bulging portions and the separation of the two liquid jets at impingement by the air jet at high air mass flow rates.

The near field characteristics of the interaction of the air jet with the other two liquid jets have not been examined in sufficient details and the way how this near field behavior is related to the drop size distribution has not been determined. Information on combined droplet size and velocity is also lacking. The objective of the present study is to provide detailed qualitative 
information on the breakup mode in the near field region using high speed photography and obtain quantitative droplet size and velocity measurements using phase Doppler anemometry (PDA) in a region downstream of the jet impingement point. The experimental setup is described below followed by the results section and conclusions.

\section{Experimental setup and measurement techniques}

This experiment is conducted with water and air as working fluids at an ambient room temperature of around $20^{\circ} \mathrm{C}$ and atmospheric pressure. The experimental program consists of flow visualization using high speed photography and droplet size and velocity measurements with phase Doppler anemometry (PDA).

A schematic of the experimental setup is shown in Fig. 1. It consists of a recirculating closed water loop and air supply system to the air nozzle. The water loop includes a plexi-glass tank, which supplies through two magnetically coupled centrifugal pumps the liquid jet nozzles. The water exiting from the liquid nozzles returns to the water tank. The air jet nozzle is supplied by air from a centralized compressed air supply system, which consists of an air compressor and flow rate regulating accessories. The air flow rate is measured by an Alicat mass flow meter with an accuracy of $\pm 0.3 \%$ reading $+0.2 \%$ F.S., while the water flow rate is measured using two calibrated Omega FLR1000 water flow meters separately. The accuracy of the water flow meter is $1 \%$. Temperature of water inside the tank is constantly monitored throughout the experiment using a K-type thermocouple to ensure that there are no significant variations in the temperature which may affect the fluid viscosity and hence the atomization performance.

The atomizer is made of three stainless steel pipe-nozzles of $0.686 \mathrm{~mm}$ internal diameter, as shown in Fig. 2. The length of the water pipes was $152.4 \mathrm{~mm}$ in length giving a length to diameter ratio $\mathrm{L} / \mathrm{D}_{\mathrm{g}}=220$, while for the air jet, the pipe was $304.8 \mathrm{~mm}$ in length. It can therefore be assumed that the flow issuing from the pipe exit is fully developed. The three pipe-nozzles are positioned on a plate articulated system with a graduated dial that allows a precise positioning and setting of the separation angle between the two water jets within the range from $60^{\circ}$ to $120^{\circ}$. The distance between the water nozzle exit and the impingement point is $10 \mathrm{~mm}$ whereas the air jet nozzle exit is positioned a distance of $12 \mathrm{~mm}$ above the impingement point. 
The three pipes are fixed on a three-dimensional computer-controlled traverse system from TSI to move the spray to different locations. The positional accuracy of the traverse system is 0.01 $\mathrm{mm}$.

A high speed camera, FASTCAM SA3 operated in background illumination provided by an LED light matrix was utilized to study the flow visualization. Images were captured with the high speed camera from two directions (front view and side view) and analyzed using the software Photron Fastcam Viewer Ver.352 at the frame rate of 15,000 fps and 20,000 fps for far and nearfield respectively, corresponding to $256 \times 256$ and $512 \times 128$ pixels. The sequence of instant camera photographs is used to record flow structure and the way the two water jets and the air jet interact with each other.

The PDA system used in the current study is a two scattering beams and three detectors standard system from TSI. In this study, two lasers beams are generated by a $313 \mathrm{~mW}$ air-cooled Argonion laser generator, which are of different wavelengths, blue $(514.5 \mathrm{~nm})$ and green $(488 \mathrm{~nm})$. Both of them are split into two beams by a Fiber light (Multicolor beam separator), and one of the two same color beams is frequency shifted by a $40 \mathrm{MHz}$ Brag cell for distinguishing reverse velocity direction. A TSI450401 transmitter probe, together with a XPD50-E expander makes the beams intersect and form the probe volume. As a droplet goes across the probe volume, light will be scattered. The TSI 450305 receiver located at an off-axis angle of $30^{\circ}$ captures the scattered light generated from droplets passing through the probe volume and focuses it on a photomultiplier PDM1000 (Photo Detector Module). The output of the photomultiplier is converted into a voltage signal, which is then processed by the FSA4000 multi-bit digital signal processor. The Flow-Sizer software is used to deal with the digital signals. The velocity of the droplet is obtained the same way as for the LDA from the frequency of the fluctuation of the light intensity based on the proportional relationship among the light intensity frequency, fringe spacing and velocity. The droplet size is obtained from the phase shift between the Doppler signals converted from the optical signals captured by the photo-detectors positioned at different angles (Hustedet et al. 2009). Settings of the PDA system are shown in Table 1. 
Table 1. Settings and parameters of the PDA system

\begin{tabular}{|c|c|c|}
\hline \multicolumn{3}{|c|}{ Transmitter Optics } \\
\hline Channel & Channel 1 & Channel 2 \\
\hline Wavelength (nm) & 514.5 & 488 \\
\hline Focal Length (mm) & 500 & 500 \\
\hline Beam Separation $(\mathrm{mm})$ & 20 & 20 \\
\hline Laser Beam Diameter $(\mathrm{mm})$ & 1.7 & 1.7 \\
\hline Beam Expander (ratio) & 2 & 2 \\
\hline Expanded Beam Separation (mm) & 40 & 40 \\
\hline Expanded Beam Diameter $(\mathrm{mm})$ & 3.4 & 3.4 \\
\hline Fringe Spacing $(\mu \mathrm{m})$ & 6.4364 & 6.1049 \\
\hline Beam Waist $(\mu \mathrm{m})$ & 96.34 & 91.37 \\
\hline Bragg Cell Frequency (MHz) & 40 & 40 \\
\hline \multicolumn{3}{|c|}{ Phase Receiver Optics } \\
\hline RVC Front Lens $f_{. l .}(\mathrm{mm})$ & \multicolumn{2}{|c|}{500} \\
\hline RVC Back Lens $f_{. l .}(\mathrm{mm})$ & \multicolumn{2}{|c|}{370} \\
\hline Slit Aperture $(\mu \mathrm{m})$ & \multicolumn{2}{|c|}{150} \\
\hline Off-axis Angle () & \multicolumn{2}{|c|}{30} \\
\hline \multicolumn{3}{|c|}{ Droplet Properties } \\
\hline Scattering Mechanism & \multicolumn{2}{|c|}{ Refraction } \\
\hline Polarization Angle & \multicolumn{2}{|c|}{ Perpendicular } \\
\hline Refractive Index of the Droplet & \multicolumn{2}{|c|}{1.33} \\
\hline Droplet Size range $(\mu \mathrm{m})$ & \multicolumn{2}{|c|}{$0.61-251.26$} \\
\hline
\end{tabular}

In the study, the laser transmitter and receiver are fixed onto an L-shape frame, so that they are on the same horizontal level to allow good and easy alignment. The measurement accuracy of the PDA system for droplet size is less than $1 \% \mathrm{D}_{\max }+1 \% \mathrm{D}_{\text {measurement, }}$ and repeatability is $0.5 \%$, while the accuracy for velocity is $<0.5 \%$ and repeatability is $0.05 \%$ (Lai, Shakal, and Troolin 2013). The presented averaged values of the droplet size and velocity measurements were based on 10,000 samples, which leads to statistical uncertainties around $2 \%$ for the Sauter mean diameter and less than $1 \%$ for the droplet velocity. With the statistical uncertainties, systematic errors and random errors taken into consideration, overall uncertainties in the Sauter mean diameter and velocity can be estimated to be $\pm 4 \%$ and $\pm 1 \%$, respectively. 


\section{Results}

\subsection{Spray structure}

Fig. 3 displays instantaneous images of the formed spray at a range of water and air flow rates. For each air flow rate, two rows of images, corresponding to different water flow rates, are displayed. The first row captures images in the $(\mathrm{Y}-\mathrm{Z})$ plane, whereas the second row relates to the $(\mathrm{X}-\mathrm{Z})$ plane. When there is no air jet $\left(\mathrm{Q}_{\mathrm{m}}=0 \mathrm{~g} / \mathrm{min}\right)$, a water sheet is generated in the plane (Y-Z) perpendicular to the plane $(\mathrm{X}-\mathrm{Z})$ formed by the liquid jets axes of Fig. 2, and the flow structure that takes place is well described by Li and Ashgriz (2006). As soon as the air jet enters into play, as shown in Fig. 3, the air flow eliminates the formation of the water sheet. As will be discussed later, the air jet now interacts individually with the water jets. This interaction is responsible for the primary atomization of the water jets. The liquid jets are then atomized, resulting in a spray that expands in a fan shape. As expected, the images display finer mists as the air flowrate is increased.

The images in Fig. 3 are obtained from a far distance from the spray and in order to examine better the detailed near field interaction between the air and water jets, close photographs shown in Fig. 4 have been recorded. Fig. 4 shows images for three water flow rates of 100, 200 and 300 $\mathrm{mL} / \mathrm{min}$. For each water flow rate, a sequence of images from both front and side views are shown at different air mass flow rates ranging from 4.38 to $27.00 \mathrm{~g} / \mathrm{min}$. The front view image is taken in plane $(\mathrm{Y}-\mathrm{Z})$ and the side view one in plane $(\mathrm{X}-\mathrm{Z})$.

The situation at hand is the one where an air jet impinges on and interacts with two liquid jets placed symmetrically on each side of it. It also shares several similarities with the interaction of a co-axial annular gas stream and a central liquid jet. The breakup phenomena in the near field, associated with the latter, have been described extensively by Lasheras et al. (1998) and Varga et al. (2003). Here, we describe the phenomena taking place and draw on the similarities that exist with the co-axial air-liquid jet arrangement. The images of Fig. 4 at relatively low gas flow rates show that the air jet interacts with the liquid jets by drawing liquid sheets or membranes surrounded by thick ligaments. These also correspond to low Weber numbers as defined in equation (1) (Varga et al. 2003). 


$$
W e=\frac{\rho_{g}\left(U_{g}-U_{l}\right)^{2} d}{\sigma}
$$

In this case, surface tension is clearly the dominating factor. At a low water flow rate of 100 $\mathrm{mL} / \mathrm{min}$, the water jet conserves more or less its core, while adopting a spiraling form. The core breaks down downstream into large lumps of liquid. For high liquid flow rates of 200 and 300 $\mathrm{mL} / \mathrm{min}$ and at low air mass flow rates up to $6.75 \mathrm{~g} / \mathrm{min}$, each liquid jet is drawn into a liquid membrane with ripples on its surface and surrounded by relatively thick ligaments. In this case of primary breakup, the liquid membranes deform into bags, which subsequently break into small droplets, while the surrounding ligaments break into larger droplets. These phenomena were also observed by Inoue et al. (2013) who referred to them as bursting bulging portions and at similar air to liquid mass flow rate ratios around 2-3\%. Fiber type ligaments (Lasheras et al. 1998) were also observed for the cases of $\mathrm{Q}_{\mathrm{L}}=200 \mathrm{~mL} / \mathrm{min}$, and $\mathrm{Q}_{\mathrm{L}}=300 \mathrm{~mL} / \mathrm{min}$ at $\mathrm{Q}_{\mathrm{m}}=13.50$ $\mathrm{g} / \mathrm{min}$. As the gas flow rates increase beyond $13.50 \mathrm{~g} / \mathrm{min}$ the liquid jets become exposed to a high velocity gas stream inclined to the liquid surface which results in the acceleration of the liquid stream. In this instance, shear breakup takes place. The jet core length is significantly reduced and there is a generation of a fine mist of droplets through a stripping process with some pulsations. This type of breakup most probably can be attributed to a Rayleigh-Taylor type instability, as discussed by Varga et al. (2003).

\subsection{Spray angles}

Spray angle refers to the angle formed by the boundaries of the area that is occupied by the water mist from the breakup of the impinging jets in the front view perspective. The mean spray angle is obtained by locating the impinging point and one point located $15 \mathrm{~mm}$ below the $\mathrm{X}$ axis of Fig. 2. The edges of the spray are obtained from an averaged image obtained using 400 instantaneous images.

Fig. 5 shows the spray angle against water jet flow rates for two air flow rates and two

impingement angles of $90^{\circ}$ and $120^{\circ}$. It can be observed that the spray angle increases with air flow rates and also linearly with the water flow rates. The spray angle is also a strong function of impingement angle as the rate of increase for $120^{\circ}$ is higher than for the $90^{\circ}$, which is 
relatively mild. As the water flowrate increases, as mentioned above, the liquid jets disintegration is much more pronounced and intense in contrast to the low water flowrates, where the spray remains more confined. The higher air flowrates produce a rapid spread of the air jet, which results in a wider spray angle.

\subsection{Droplet sizes}

Radial profiles along the $\mathrm{Y}$ direction of $\mathrm{D}_{32}$ distribution in the $\mathrm{Y}-\mathrm{Z}$ plane at different $\mathrm{Z}$ positions from the impingement point are discussed next. Fig. 6 (a) illustrates the radial profiles of the $\mathrm{D}_{32}$ for a water flow rate of $250 \mathrm{~mL} / \mathrm{min}$ and air mass flow rate of $13.50 \mathrm{~g} / \mathrm{min}$ for the $90^{\circ}$ separation angle of the liquid jet axes. Fig. 6 (b) is the corresponding cloud distribution. It can be seen that the $\mathrm{D}_{32}$ profiles reveal a central region with low values of $\mathrm{D}_{32}$ between 55 and $80 \mu \mathrm{m}$. For each axial location, the droplet diameter increases as we move outwards to reach maximum values of around $120 \mu \mathrm{m}$. This can be explained by the fact that the central region is where the strongest interaction between the liquid jets and air jet takes place. The outer region located in the near field does not see much of the air jet initially. The difference between the $\mathrm{D}_{32}$ in the center and outer region decreases with downstream distance, in agreement with the findings of Avulapati and Venkata (2013). As the droplets progress downstream, the value of the SMD close to the axis decreases due to possible further droplet break-up when they interact with the surrounding air flow and further redistribution of the droplets in the surrounding spray, including the $\mathrm{X}-\mathrm{Z}$ plane.

To study the effect of water flow rates on droplet size distribution, $D_{32}$ along the vertical axis $Z$ is measured and shown in Fig. 7, which illustrates the actual $\mathrm{D}_{32}$ for several water flow rates when the air mass flow rate is equal to $13.50 \mathrm{~g} / \mathrm{min}$ for $90^{\circ}$ impingement angle. One can observe higher values of $\mathrm{D}_{32}$ result for higher water flow rates. Further, for each flow rate the droplet diameter decreases with axial distance and increase again beyond a distance of approximately 200 air nozzle diameters, indicative of droplet coalescence.

Previous measurements of $\mathrm{D}_{32}$ in liquid-liquid impingment atomizers without air revealed much larger droplet sizes for approximately the same injection conditions as used here. For example, Shen et al. (1997) measured the size of droplets generated from two impinging water jets of 0.79 
$\mathrm{mm}$ in diameter to be over $300 \mu \mathrm{m}$ when the water jets impinge at a mean velocity of $12.5 \mathrm{~m} / \mathrm{s}$. Baek et al. (2011) using $700 \mu \mathrm{m}$ diameter impinging water jets at $90^{\circ}$ measured $\mathrm{D}_{32}$ within the range of $105 \mu \mathrm{m}$ to $525 \mu \mathrm{m}$ for water jet velocities between $18.57 \mathrm{~m} / \mathrm{s}$ and $55.05 \mathrm{~m} / \mathrm{s}$. Indiana et al. (2015) reported, for nozzle pipe diameter of $510 \mu \mathrm{m}$ and impinging angles of $45^{\circ}, 60^{\circ}$ and $75^{\circ}$, $\mathrm{D}_{32}$ in the range of 40 to $90 \mu \mathrm{m}$, with the $40 \mu \mathrm{m}$ size obtained at relatively high jet Reynolds numbers around 40,000. The air jet therefore enables the impinging jets to generate droplets of smaller size with moderate water jet velocities.

The effect of impinging angle of water jets on droplets size distribution is investigated by comparison of $\mathrm{D}_{32}$ distributions along spray axis at impinging angles of $60^{\circ}, 90^{\circ}$ and $120^{\circ}$ at the same air and water flow rates. Water flow rates are 100, 200 and $300 \mathrm{~mL} / \mathrm{min}$, while keeping air flow rate at $\mathrm{Q}_{\mathrm{m}}=27.00 \mathrm{~g} / \mathrm{min}$. As shown in Fig. 8, generally $\mathrm{D}_{32}$ is smaller at a larger impinging angle due to the higher impact pressure, which pushes more water volume away from the impinging point, leaving less water in the central region of the spray. However, there is no obvious difference between the cases of $60^{\circ}$ and $90^{\circ}$ at $\mathrm{Q}_{\mathrm{L}}=100 \mathrm{~mL} / \mathrm{min}$ about $90 \mathrm{~mm}$ downstream of the impinging point and the cases of $90^{\circ}$ and $120^{\circ}$ at $\mathrm{Q}_{\mathrm{L}}=300 \mathrm{~mL} / \mathrm{min}$, which is attributed to the fact that at around $Z=90 \mathrm{~mm}$, droplets at each case are of similar size, and they are exposed to the air jets of same mass flow rate.

Spray characteristics can be expressed in terms of global parameters, such as the exit pipe conditions without consideration of the local structure of the flow. Traditionally, parameters such as gas to liquid ratio, Weber number and air-liquid momentum ratio (ALMR) have been considered to model and represent the variation of the non-dimensionalized $\mathrm{D}_{32}$. These are shown in Fig. 9, 10 and 11. ALMR is defined in equation (2) (Boden et al. 1999).

$$
A L M R=\frac{\dot{m}_{g} U_{g}}{\dot{m}_{l} U_{l}}
$$

Fig. 9 shows the normalized $\mathrm{D}_{32} / \mathrm{D}_{\mathrm{g}}$ against the gas-to-liquid mass ratio (GLR). The measurements of Avulapati and Venkata (2013) are also shown. The current measurement set extends the range of GLR considered by Avulapati and Venkata (2013) beyond the GLR value of 
0.15. In this region, $\mathrm{D}_{32}$ continues to fall and level off beyond a GLR of 0.2. Therefore, increases of GLR beyond this value will provide very little influence on the break up process.

Fig. 10 displays the $\mathrm{D}_{32}$ normalized by the air nozzle diameter as a function of the square root of the relative aerodynamic Weber number $\mathrm{We}^{1 / 2}$, in which $\mathrm{D}_{32} / \mathrm{D}_{\mathrm{g}}$ decreases exponentially with the increasing $\mathrm{We}^{1 / 2}$, due to the strong interaction caused by the velocity difference between the air and water jet velocities. The impinging angle also contributes to the water jets atomization and its influence becomes weak with the increasing aerodynamic Weber number.

Englebert et al. (1995) and Boden et al. (1999) have shown that, for coaxial airblast atomizers and impinging jet atomizers, the ALMR is the appropriate parameter describing the atomization process based on the fact that momentum can be related to the local shear leading to breakup of the liquid jets. Hence the variation in $\mathrm{D}_{32} / \mathrm{Dg}$ as a function of ALMR is presented in Fig. 11. In contrast to the relative aerodynamic Weber number, Fig. 11 suggests better correlation with ALMR. The figure also indicates that there is a limit to atomization efficiency, so that $\mathrm{D}_{32} / \mathrm{Dg}$ remains around 0.05 beyond a critical ALMR of 5 and the effect of the impingement angle also reduces. This can be explained by the fact that as finer droplets are produced close to the impingement point; their ability to follow the air flow is increased with reduced slip, which leads to more stable droplet diameters closer to the impingement point.

\subsection{Droplet velocities}

The Y-profiles of the mean axial velocity component $\mathrm{W}$ at several axial poistions are illustrated in Fig. 12 (a) for water and air flow rates of $250 \mathrm{~mL} / \mathrm{min}$ and $13.50 \mathrm{~g} / \mathrm{min}$. The profiles assume the well known bell shape for jets. The incoming air jet serves therefore to modulate these profiles. The profiles diffuse with downstream distance with a decrease of velocity in the central region.

The profiles of the mean radial velocity component $\mathrm{V}$ along the $\mathrm{Y}$ direction are shown in Fig. 12 (b). The magnitude of this component is approximately about $15 \%$ of the mean axial component. Radial velocities are initially large due to the spreading of the spray and reduce with downstream distance when the droplets assume almost vertical trajectories. 
The decay of the centerline mean axial W-velocity of droplets located along the spray axis is shown in Fig. 13. At a fixed air mass flow rate $\mathrm{Q}_{\mathrm{m}}=27.00 \mathrm{~g} / \mathrm{min}$, the impingement angle has little, if any, influence on the mean velocities of the droplets. These are really modulated and dominated by the central gas jet momentum. The momentum penetration of the spray is little affected by the spray angles. Fig. 13 indicates the trend that the velocity decreases with increasing distance from the nozzle exit, which is caused by the air jet expansion and increasing air resistance.

Fig. 14 displays the root mean square (RMS) of droplet velocity fluctuations denoting the turbulent intensity of the droplet motion. W-RMS decreases from the spray center region to the outer region and becomes smaller as droplets proceed downwards, indicating a decrease in the turbulent intensity of the droplet motion. V-RMS is about half of W-RMS, but it presents a different trend. For most of the positions measured, both the center and side regions have similar value of RMS, so along the Y-axis, the turbulent intensity of the droplet motion in the radial direction is similar. The W-RMS does not change much with impinging angle, as presented in Fig. 15.

\section{Conclusions}

In this study, a new configuration of water-air impinging jets is studied. Flow visualization and droplet size and velocity measurements are used to obtain detailed information on the spray structure, liquid break up process and the resulting droplet size and velocity spatial distributions.

In the flow visualization, both far and near fields of the spray are considered at several water and air flow rates for different liquid jet impingement angles. The addition of an air jet in the waterair impinging jets atomizer promotes the atomization. Spray angle shows an increasing trend with increases of water jet exit velocity due to the fact that higher water jet momentum results in larger impact force, which makes the droplets move outwards. Generally, the spray angle appears to be larger at a larger impinging angle with the same air and water flow rates, since at a higher impinging angle, the horizontal component momentum of the water jet is larger, which leads to a stronger impact. 
The size of liquid droplets is smallest in the central region of the spray, where $\left(\mathrm{D}_{32}\right)_{\min }$ is about $50 \mu \mathrm{m}$ when $\mathrm{Q}_{\mathrm{L}}=250 \mathrm{~mL} / \mathrm{min}, \mathrm{Q}_{\mathrm{m}}=13.50 \mathrm{~g} / \mathrm{min}$, and $2 \theta=90^{\circ}$. It increases towards the outer region due to the fact that the air jet flows towards the spray central region and the ligaments in the central part suffer large aerodynamic pressure force than those on the lateral sides. This leads to increased air jet penetration while breaking the water ligaments, making the larger droplets move towards the outer periphery of the spray. The size of the droplets decreases also with increasing axial distance from the impinging point and then increases again due to coalescence. Normalized Sauter mean diameter with gas nozzle diameter decreases with gas-toliquid ratio (GLR) and air-to-liquid momentum flux ratio (ALMR) and then remains almost constant beyond a value of 0.13 and 5 for GLR and ALMR respectively. It also decreases exponentially with increasing aerodynamic Weber number and impinging angle.

The mean axial velocities of droplets are the largest in the spray center and decrease towards both sides of the spray at $\mathrm{Q}_{\mathrm{m}}=13.50 \mathrm{~g} / \mathrm{min}$ and $2 \theta=90^{\circ}$. They are modulated by the air jet velocity. At higher air flow rate of $\mathrm{Q}_{\mathrm{m}}=27.00 \mathrm{~g} / \mathrm{min}$, the impinging angle has limited influence on the vertical mean axial velocity development.

\section{Acknowledgements}

The authors gratefully acknowledge the support from the Petroleum Institute, Abu Dhabi, UAE in the form of a visiting graduate assistant grant to Y. Xia.

\section{References}

Ashgriz, N., 2011. Impinging jet atomization. Chap 30. Handbook of Atomization and Sprays, ed: Springer (2011) 685-707.

Avulapati, M. M., Venkata, R. R., 2013. Experimental studies on air-assisted impinging jet atomization. International Journal of Multiphase Flow. 57, 88-101.

Baek, G., Kim, S., Han, J., Kim, C., 2011. Atomization characteristics of impinging jets of gel material containing nanoparticles. Journal of Non-Newtonian Fluid Mechanics. 166(21), 12721285 .

Boden, J. C., Hardalupas, Y. Krenteras, P. Taylor A.M.K.P., 1999. Spray characteristics from free impinging air and liquid jets. ILASS 1999: 15th European Conference on Liquid Atomization and Spray Systems. Toulouse, France. 
Bush, J. W., Hasha, A. E., 2004. On the collision of laminar jets: fluid chains and fishbones. Journal of Fluid Mechanics. 511, 285-310.

Chen, X., Ma, D., Yang, V., Popinet, S., 2013. High-fidelity simulations of impinging jet atomization. Atomization and Sprays. 23(12), 1079-1101

Chigier, N., Farago, Z., 1992. Morphological classification of disintegration of round liquid jets in a coaxial air stream. Atomization and Sprays. 2(2),137-153.

Choo, Y., Kang, B., 2007. The effect of jet velocity profile on the characteristics of thickness and velocity of the liquid sheet formed by two impinging jets. Physics of Fluids (1994-present). 19(11), 112101.

Dombrowski, N. D., Hooper, P., 1964. A study of the sprays formed by impinging jets in laminar and turbulent flow. Journal of Fluid Mechanics. 18(03), 392-400.

Engelbert, C., Hardalupas, Y., Whitelaw, J., 1995. Breakup phenomena in coaxial airblast atomizers. Proceedings of the Royal Society of London, Series A, 451, 189-229

Hardalupas, Y., Whitelaw, J., 1996. Interaction between sprays from multiple coaxial airblast atomizers. Journal of Fluids Engineering. 118(4), 762-771.

Husted, B. P., Petersson, P., Lund, I., \& Holmstedt, G., 2009. Comparison of PIV and PDA droplet velocity measurement techniques on two high-pressure water mist nozzles. Fire safety journal. 44(8), 1030-1045.

Ibrahim, E., Przekwas, A., 1991. Impinging jets atomization. Physics of Fluids A: Fluid Dynamics (1989-1993), 3(12), 2981-2987.

Indiana, C., Bellenoue, M., Boust, B., 2015. Experimental Investigations of Drop Size Distributions with Impinging Liquid Jets Using Phase Doppler Anemometer. International Journal of Energetic Materials and Chemical Propulsion. 14(3). 241-264.

Inoue, C., Watanabe, T., Himeno, T., Uzawa, S. 2013. Impinging Atomization Enhanced by Microjet Injection-effect, mechanism and optimization, 49th AIAA/ASME/SAE/ASEE Joint Propulsion Conference (pp. 3705).

Inoue, C., Shimizu, A., Watanabe, T., Himeno, T., Uzawa, S. 2015. Numerical and Experimental Investigation On Spray Flux Distribution Produced By Liquid Sheet Atomization, ASME Turbo Expo 2015 GT2015-43364, June 15-19 Montreal, Canada.

Jung, S., Hoath, S. D., Martin, G. D., Hutchings, I. M., 2010. Atomization patterns produced by the oblique collision of two Newtonian liquid jets. Physics of Fluids (1994-present). 22(4), 042101.

Lasheras, J., Villermaux, E., Hopfinger, E., 1998. Break-up and atomization of a round water jet by a high-speed annular air jet. Journal of Fluid Mechanics. 357, 351-379.

Lai, W., Shakal, J., Troolin, D. (2013). Accuracy, Resolution, and Repeatability of Powersight PDPA and LDV Systems. TSI Technical Note P(5001520), A4.

Lefebvre, A., 1988. Atomization and sprays (Vol. 1040): CRC press. 
Li, R., Ashgriz, N., 2006. Characteristics of liquid sheets formed by two impinging jets. Physics of Fluids (1994-present). 18(8), 087104.

Ma, Y.-c., Bai, F.-q., Chang, Q., Yi, J.-m., Jiao, K., Du, Q., 2015. An experimental study on the atomization characteristics of impinging jets of power law fluid. Journal of Non-Newtonian Fluid Mechanics. 217, 49-57.

Mansour, A., Chigier, N., 1990. Disintegration of liquid sheets. Physics of Fluids A: Fluid Dynamics (1989-1993). 2(5), 706-719.

Mohan, A. M., Anand, T., Ravikrishna, R., 2012. Experimental spray characterisation of airassisted impinging jets.

Shen, Y., Mitts, C., Poulikakos, D., 1997. Holographic investigation of the effect of elevated ambient temperature on the atomization characteristics of impinging jet sprays. Atomization and Sprays. 7(2), 123-142.

Sutton, G. P., Biblarz, O., 1978. Rocket propulsion Elements, 7th ed., John Wiley and Sons, New York.

Sutton, P., 1986. Rocket Propulsion Elements-An Introduction to the Engineering of Rockets, 5th ed., John Wiley and Sons.

Varga, C., Lasheras, J. C., Hopfinger, E., 2003. Initial breakup of a small-diameter liquid jet by a high-speed gas stream. Journal of Fluid Mechanics. 497, 405-434.

Vassallo, P., Ashgriz, N., Boorady, F., 1992. Effect of flow rate on the spray characteristics of impinging water jets. Journal of Propulsion and Power. 8(5), 980-986.

Zaremba, M., Weiß, L., Malý, M., Wensing, M., Jedelský, J., Jícha, M., 2017. Low-pressure twin-fluid atomization: Effect of mixing process on spray formation. International Journal of Multiphase Flow. 89, 277-289. 


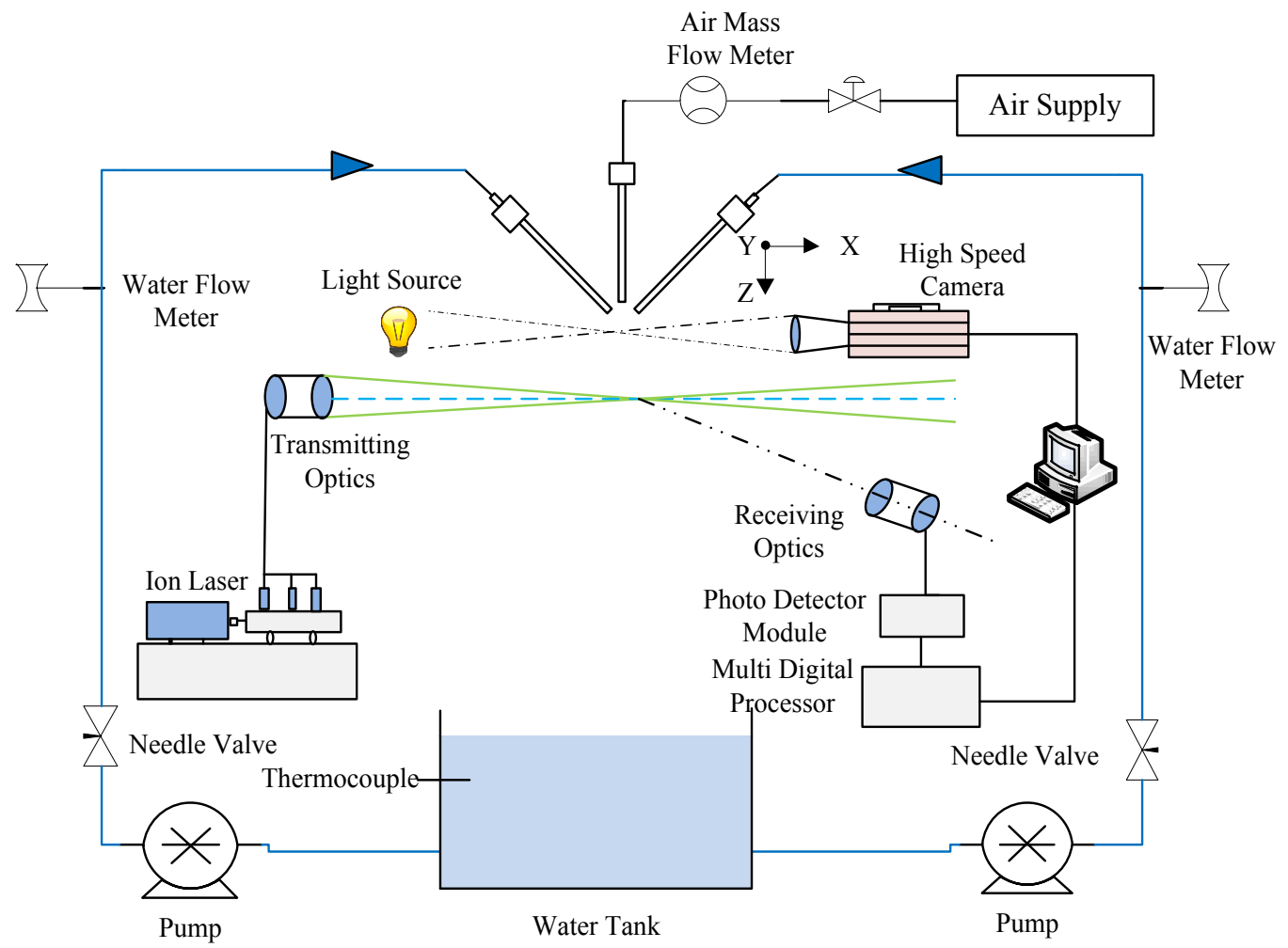

Fig. 1. Schematic of experimental setup
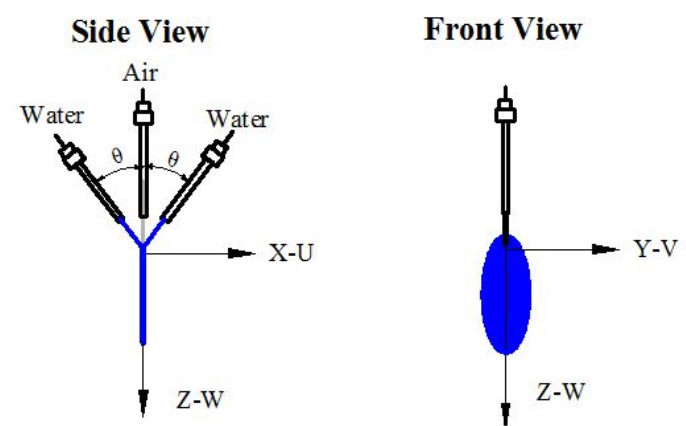

Fig. 2. Schematic of the injector geometry (water jet pre-length is $10 \mathrm{~mm}$ and air jet pre-length is $12 \mathrm{~mm})$ 


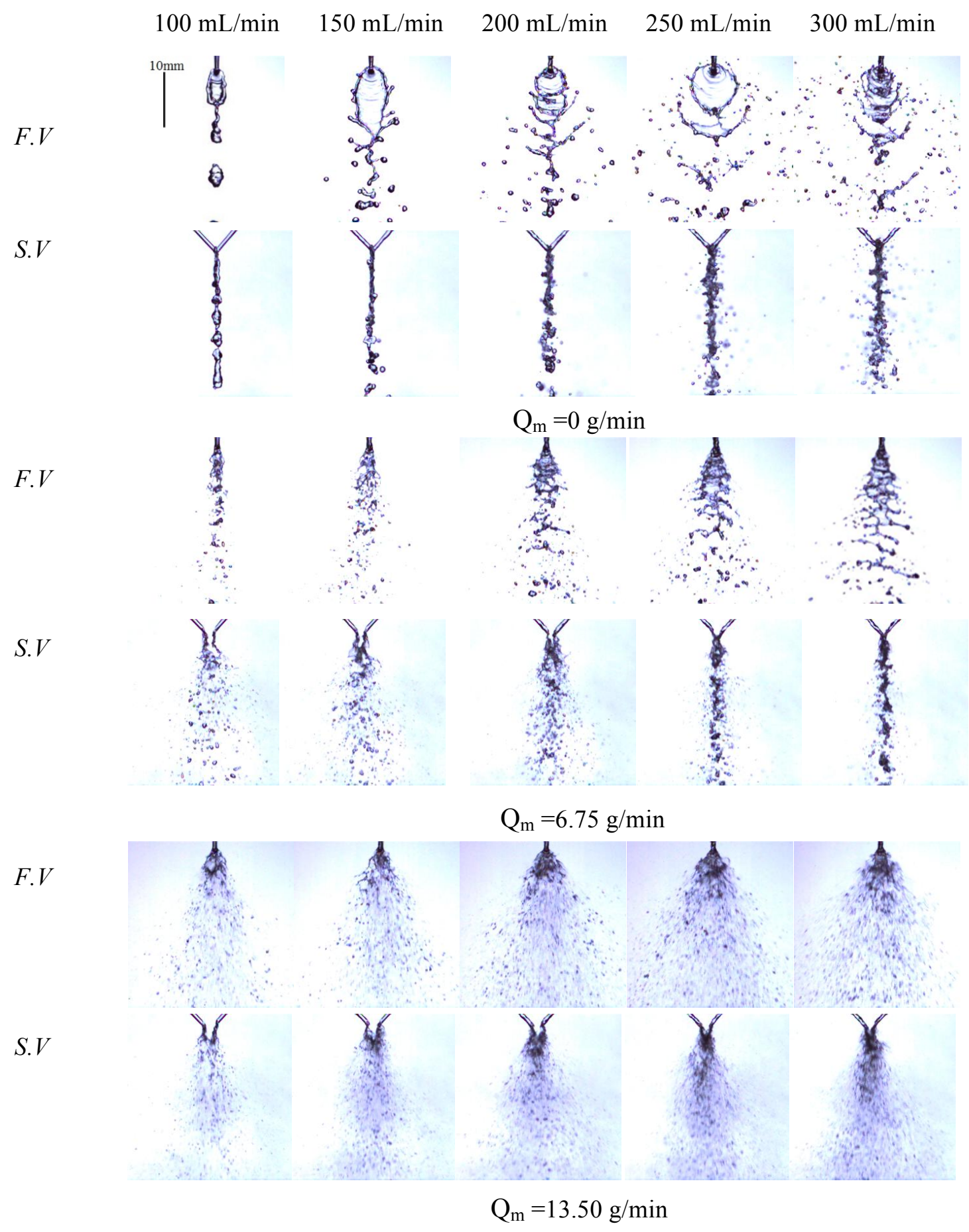




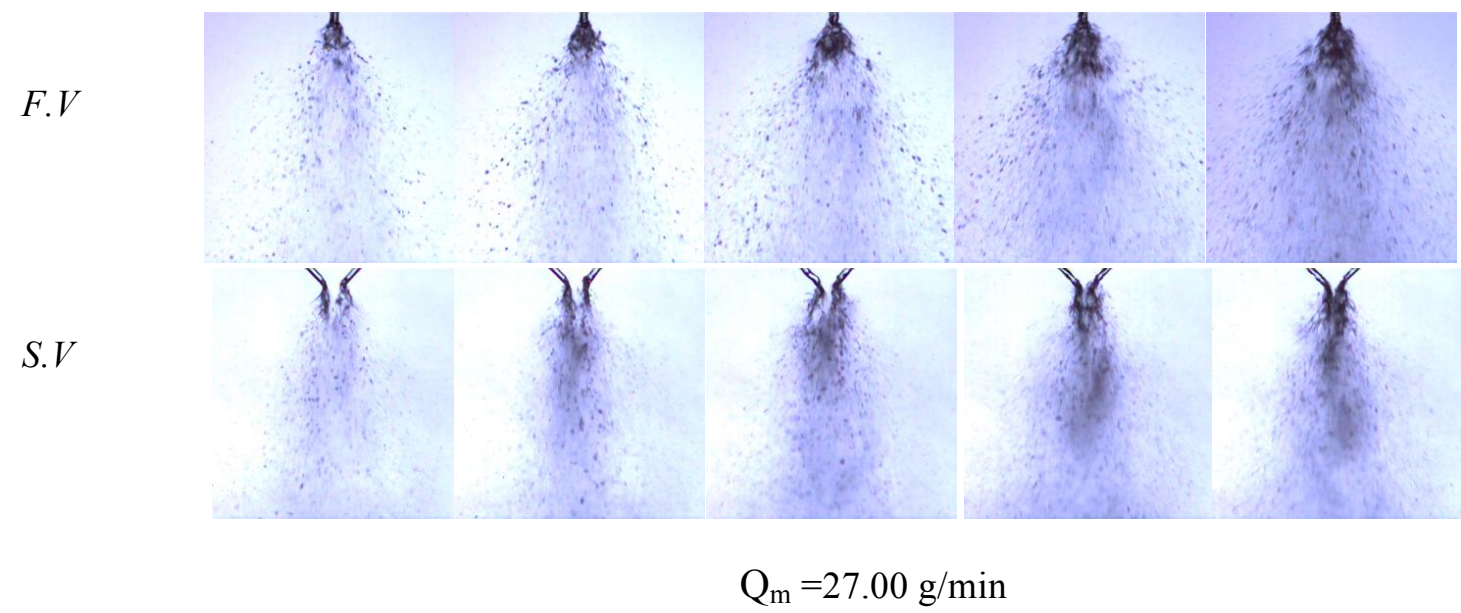

Fig. 3. Images of Spray Structure at various water and air flow rates 


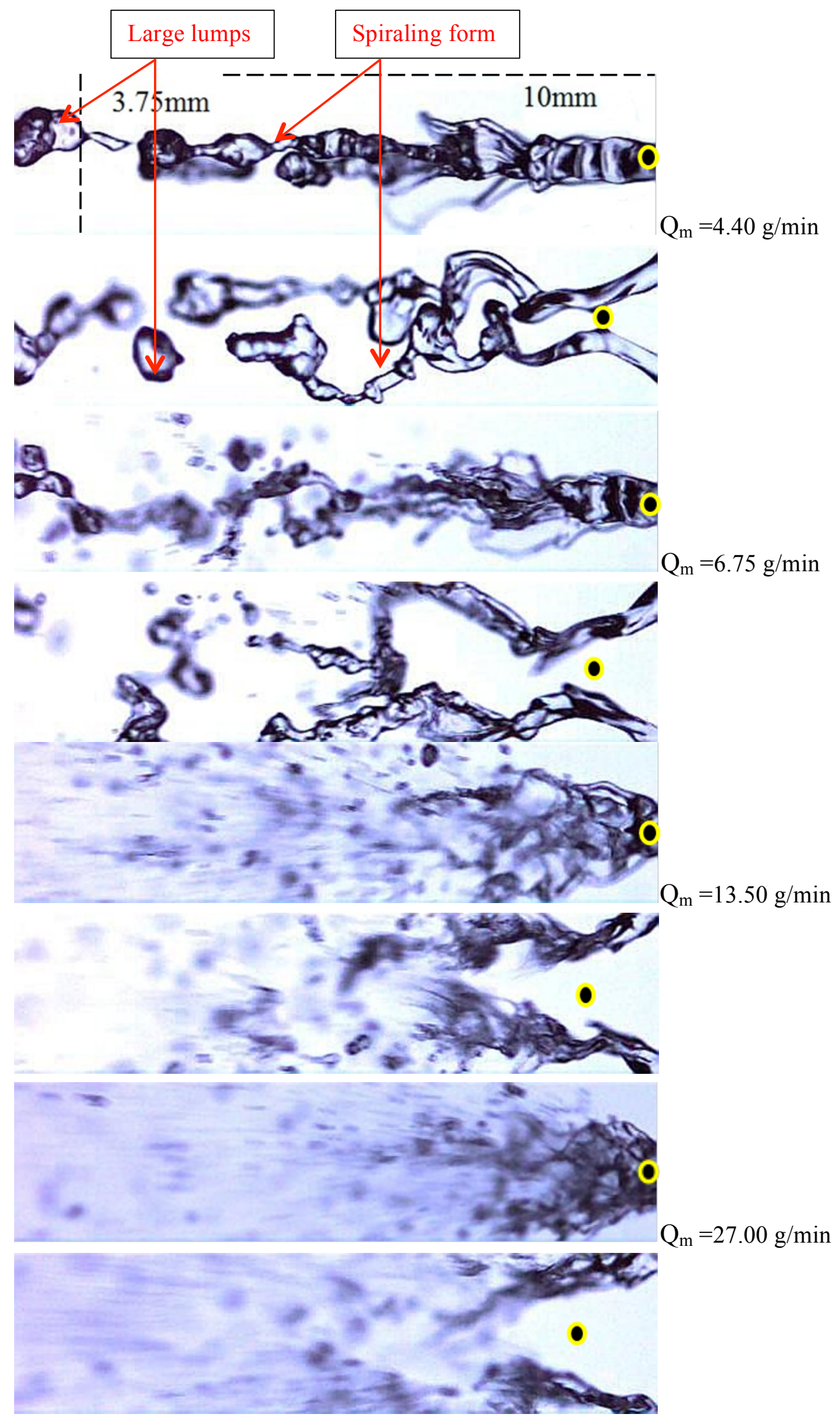

(a) $\mathrm{Q}_{\mathrm{L}}=100 \mathrm{~mL} / \mathrm{min}$ 


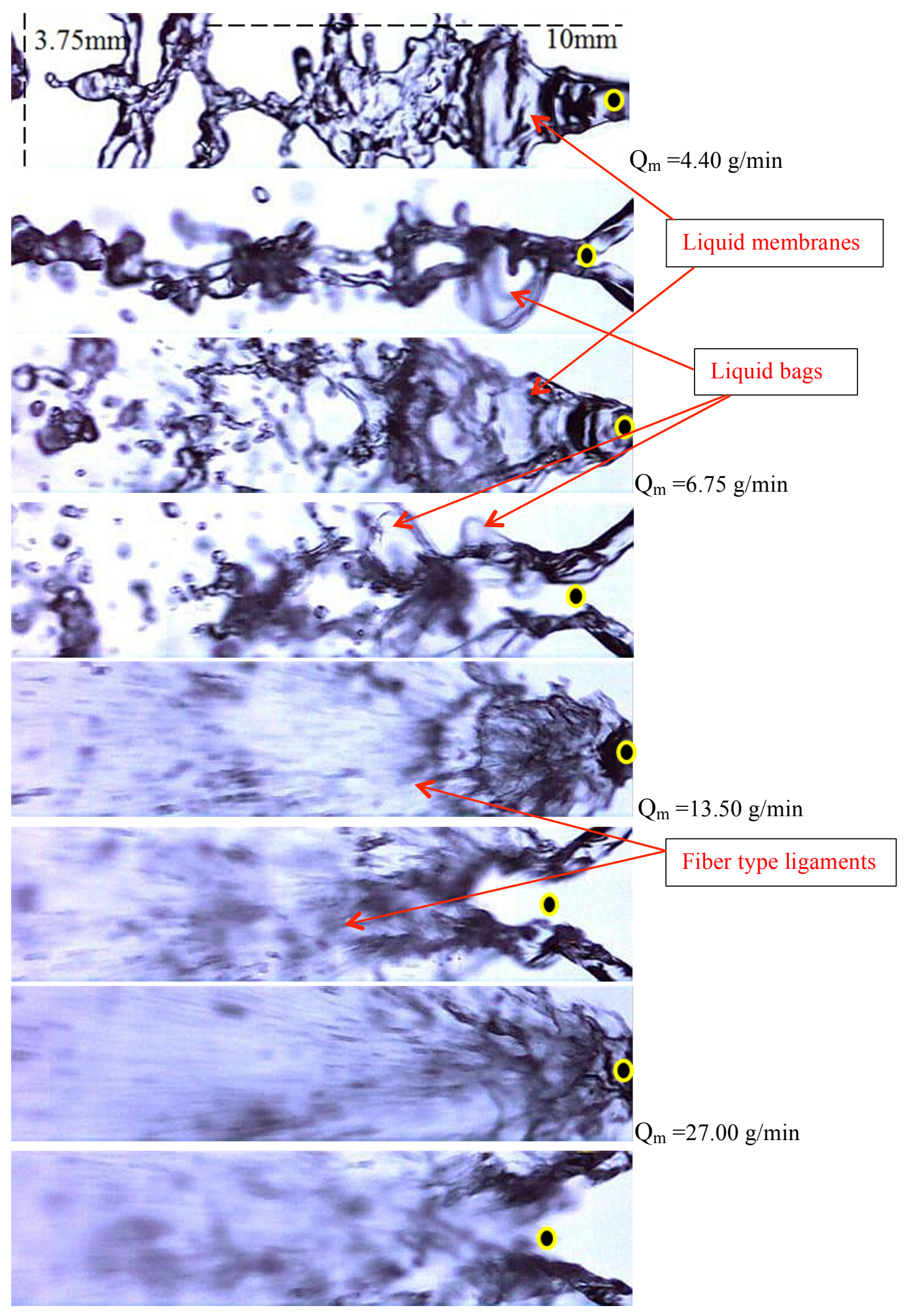

(b) $\mathrm{Q}_{\mathrm{L}}=200 \mathrm{~mL} / \mathrm{min}$ 


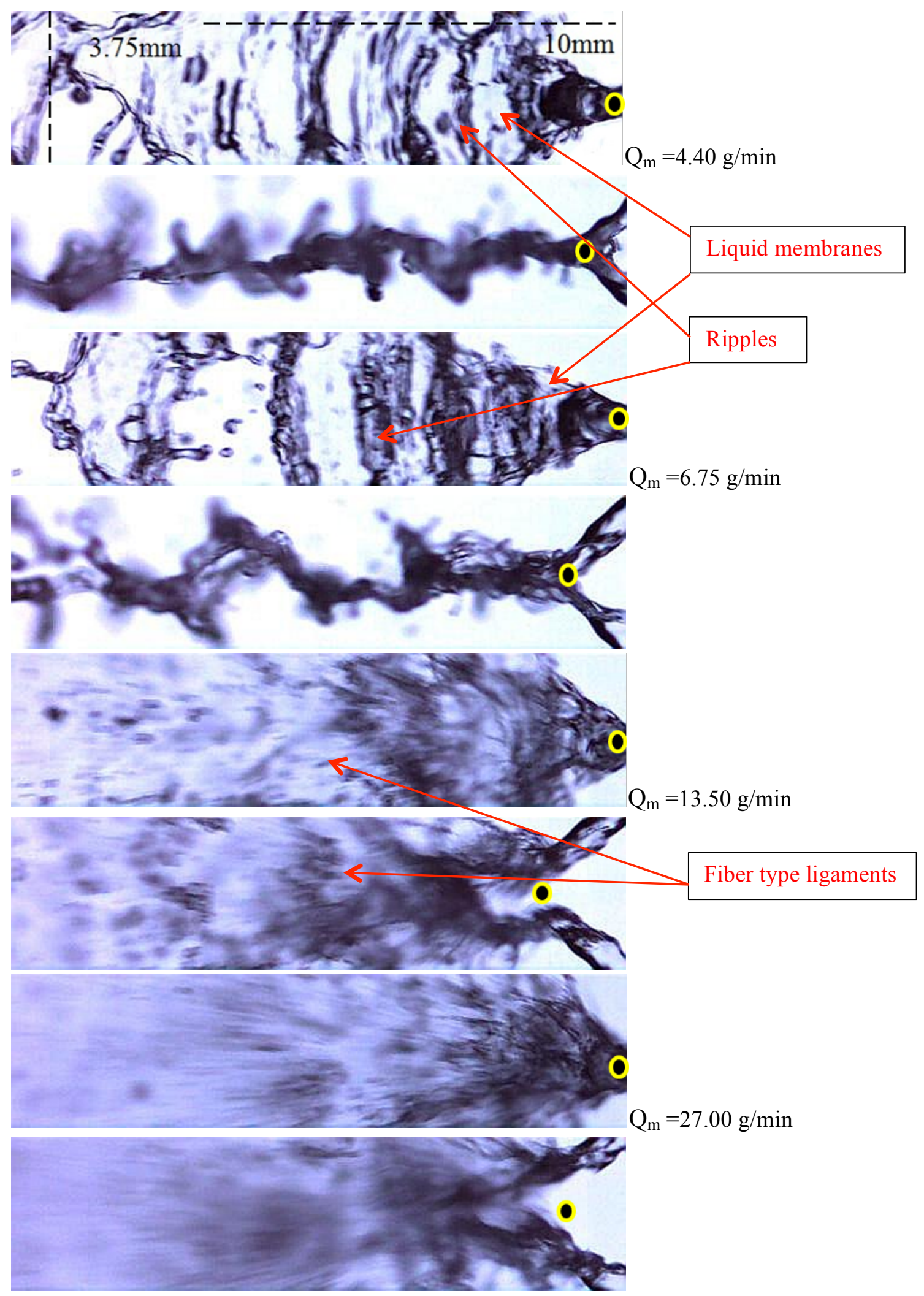

(c) $\mathrm{Q}_{\mathrm{L}}=300 \mathrm{~mL} / \mathrm{min}$

Fig. 4. Close images at $2 \theta=90^{\circ}$ (Yellow/black spot indicates the geometric point of impingement). 


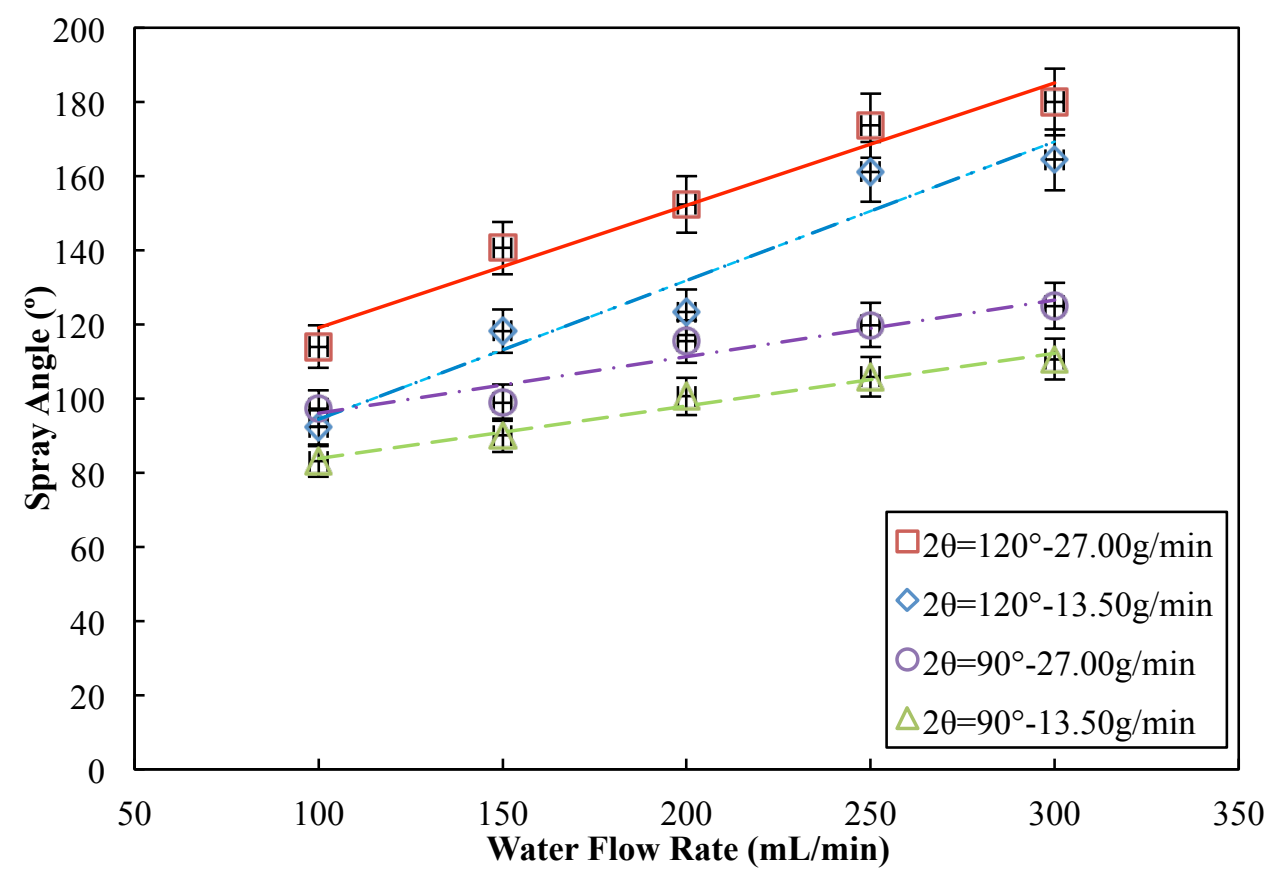

Fig. 5. Spray angles at $2 \theta=90^{\circ}$ and $120^{\circ}$ at different air mass flow rates. 


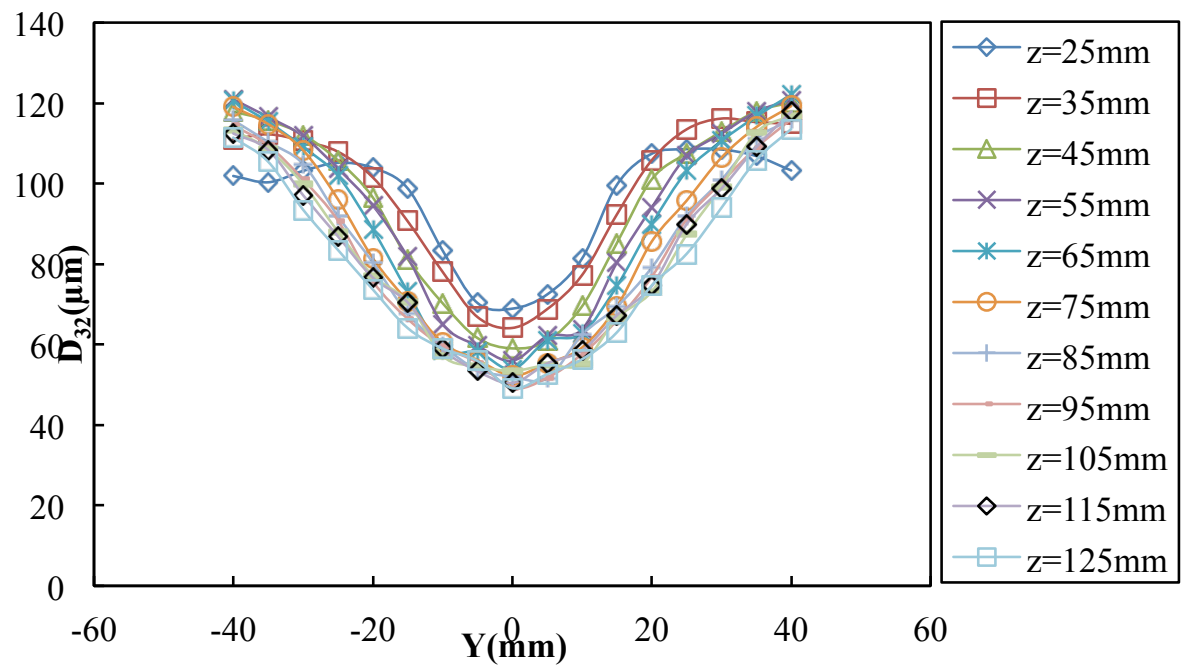

(a)

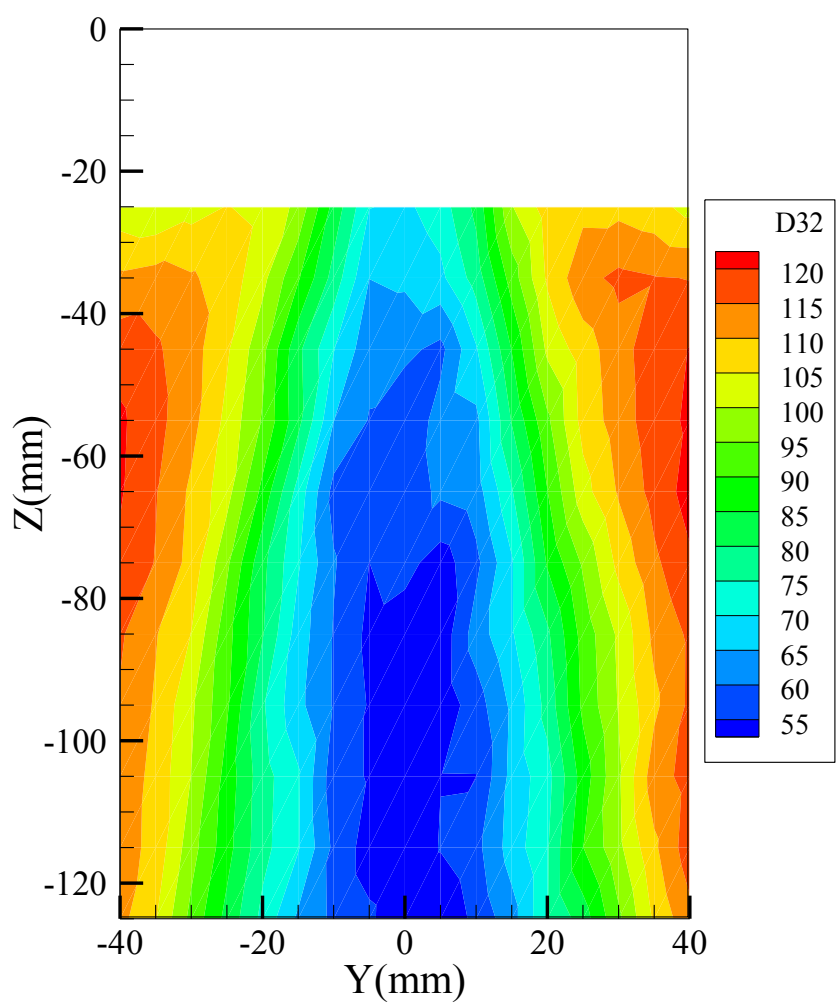

(b)

Fig. 6. Variation of $D_{32}(\mu \mathrm{m})$ with radial locations at $Q_{L}=250 \mathrm{~mL} / \mathrm{min}, Q_{m}=13.50 \mathrm{~g} / \mathrm{min}$ and $2 \theta=90^{\circ}$ 


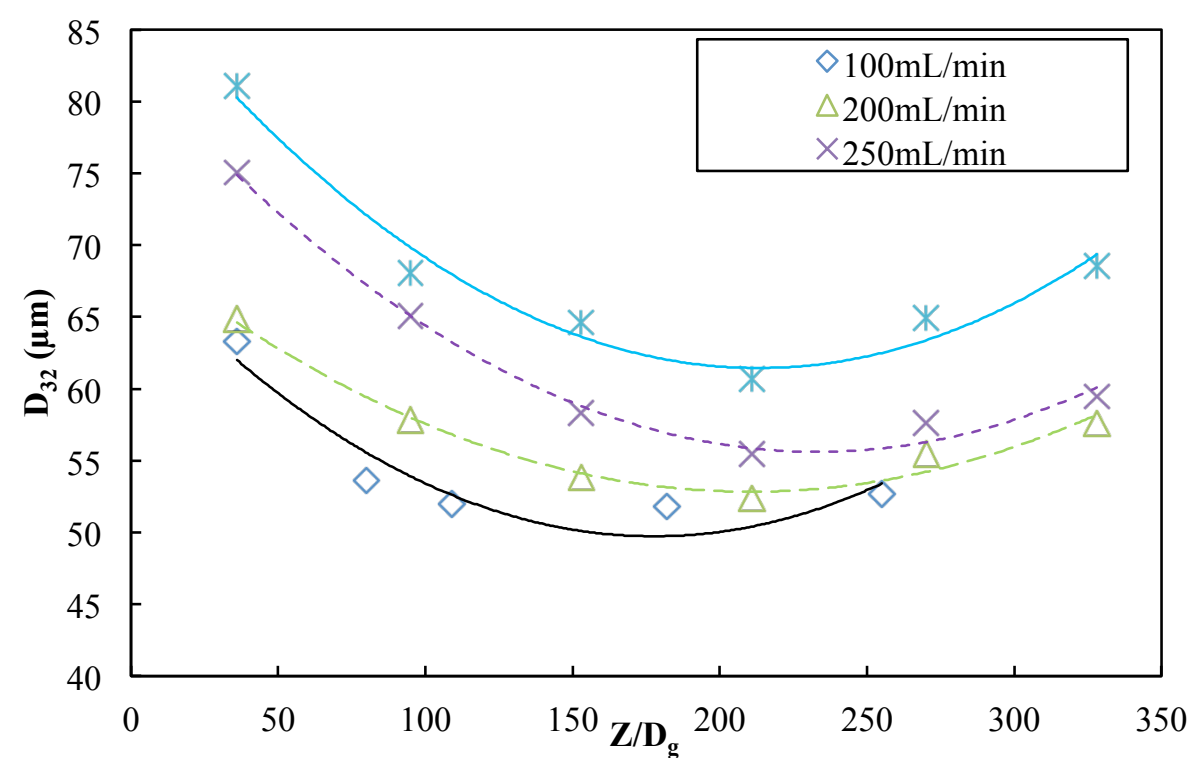

Fig.7. $\mathrm{D}_{32}$ distribution along the spray axis at air mass flow rate of $\mathrm{Q}_{\mathrm{m}}=13.50 \mathrm{~g} / \mathrm{min}$ 

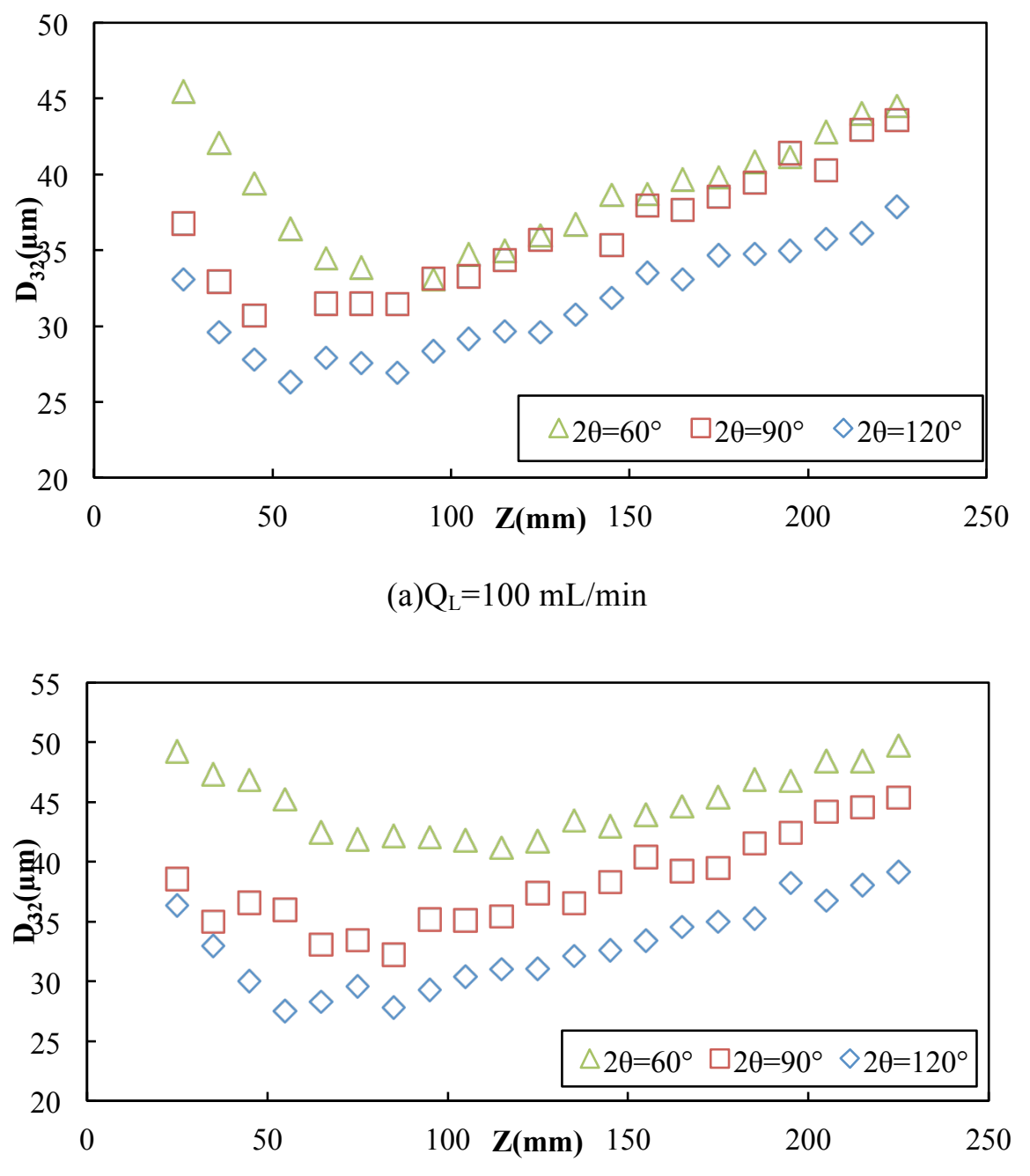

(b) $\mathrm{Q}_{\mathrm{L}}=200 \mathrm{~mL} / \mathrm{min}$

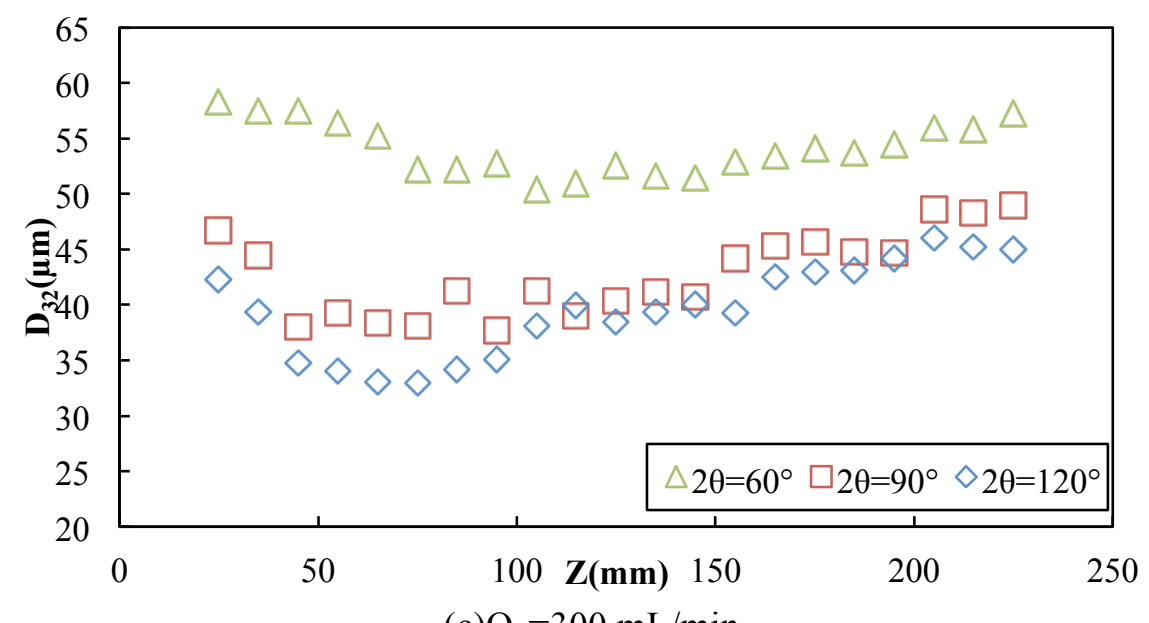

(c) $\mathrm{Q}_{\mathrm{L}}=300 \mathrm{~mL} / \mathrm{min}$

Fig. 8. $D_{32}$ distribution along the spray axis at $Q_{m}=27.00 \mathrm{~g} / \mathrm{min}$ 


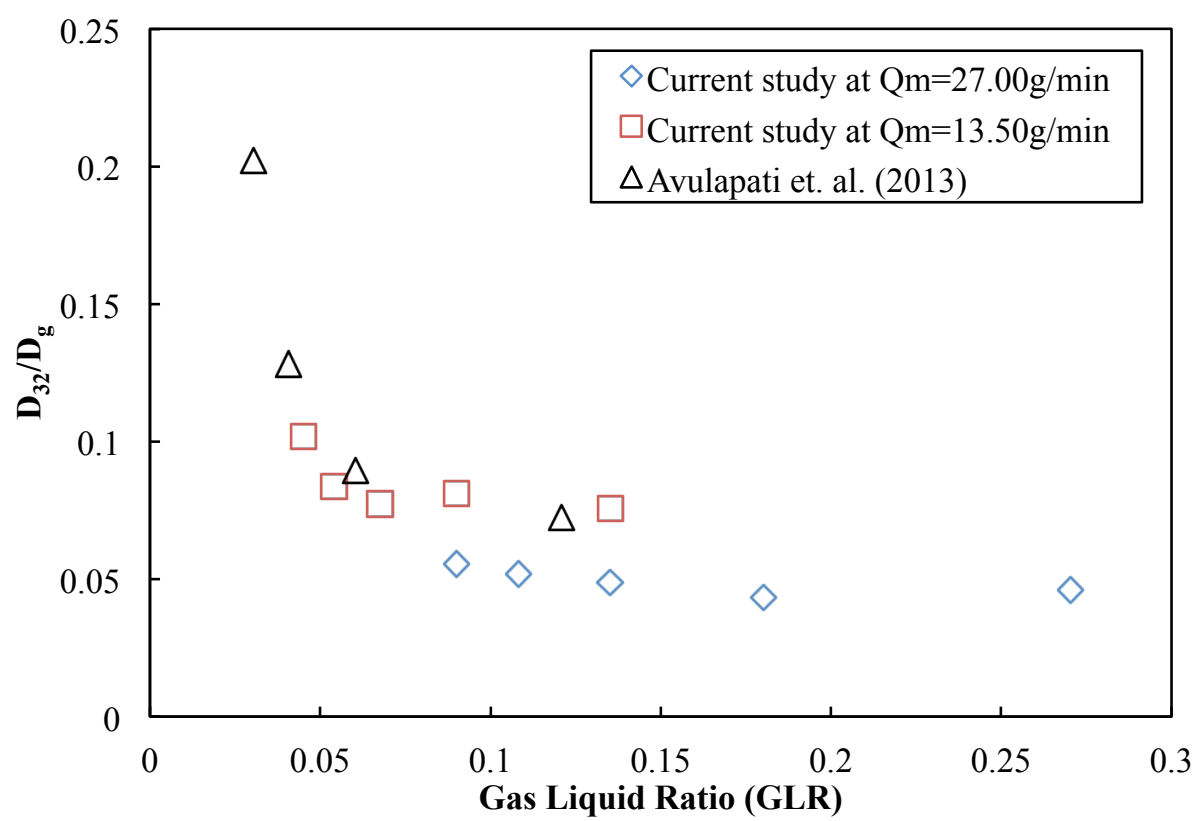

Fig. 9. $D_{32} / D_{g}$ against GLR in the spray center at $Z=75 \mathrm{~mm}$

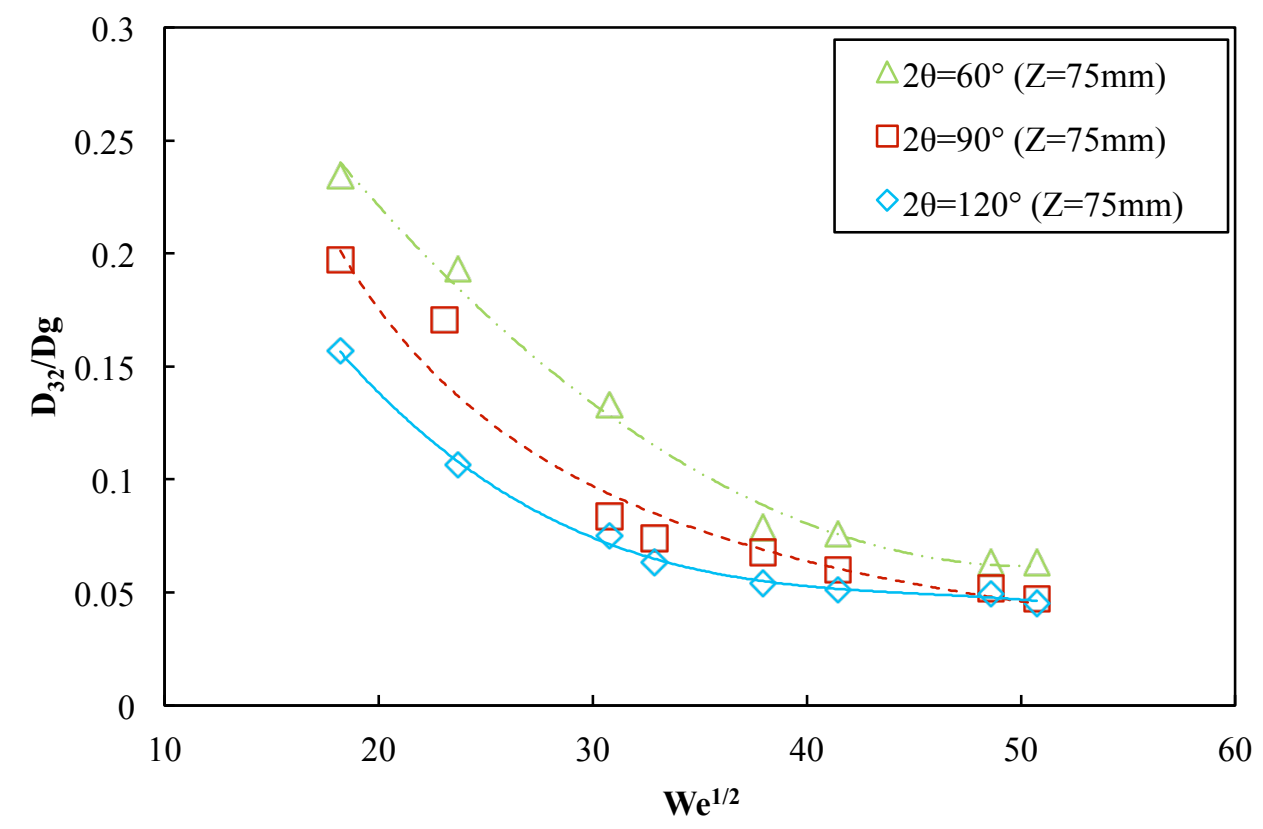

Fig. 10. $D_{32} / D_{g}$ distribution as a function of $W e^{1 / 2}$ 


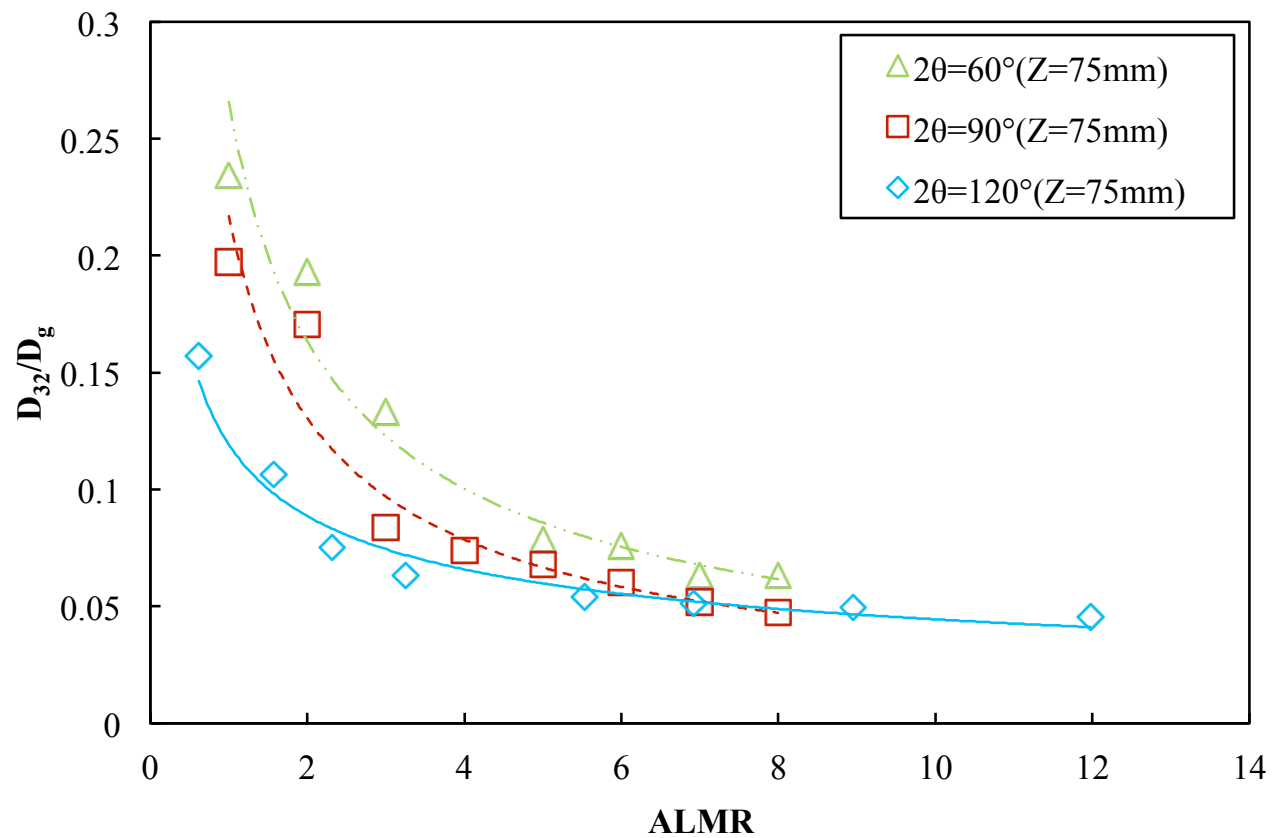

Fig. 11. $D_{32} / D_{g}$ distribution as a function of air-to-liquid momentum ratio (ALMR) 


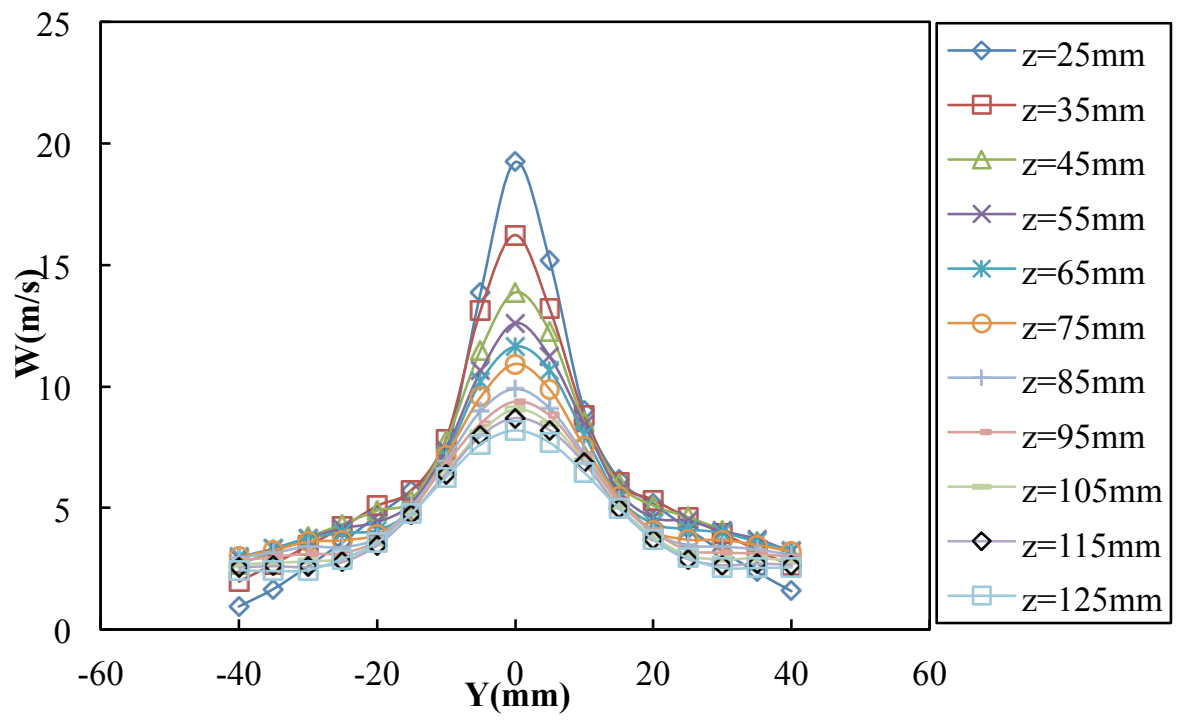

(a)

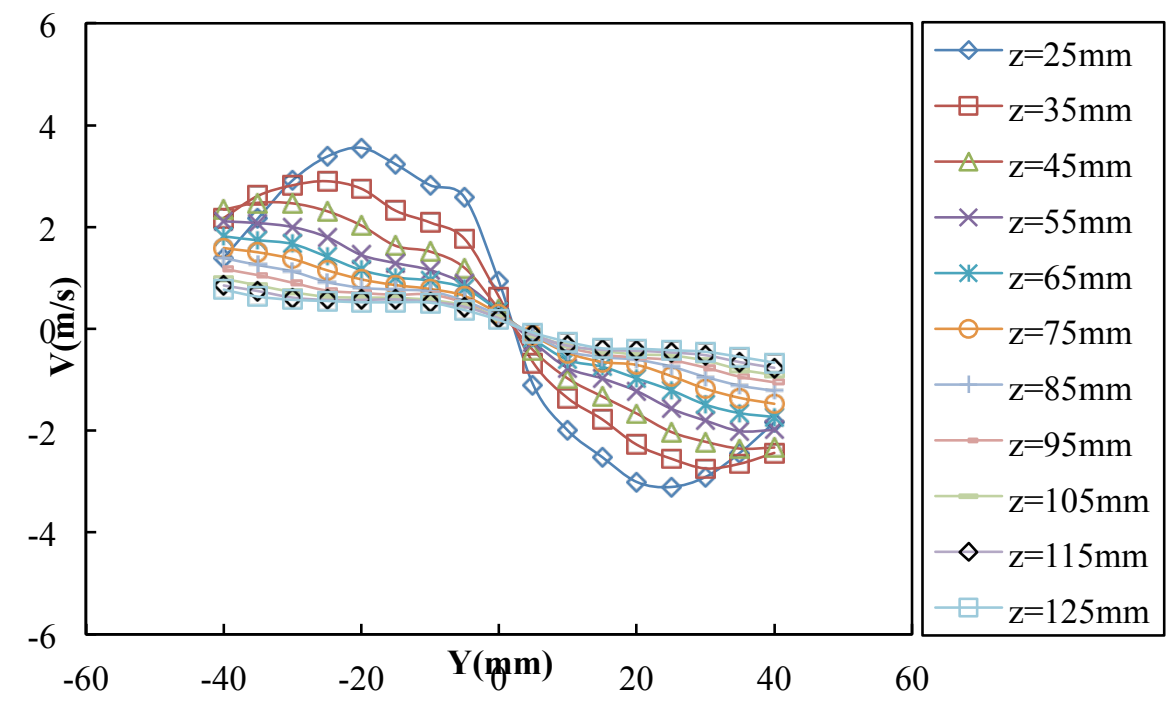

(b)

Fig. 12. Droplet mean axial (W) and radial (V) velocities for $\mathrm{Q}_{\mathrm{L}}=250 \mathrm{~mL} / \mathrm{min}$, $\mathrm{Q}_{\mathrm{m}}=13.50 \mathrm{~g} / \mathrm{min}$ and $2 \theta=90^{\circ}$ 


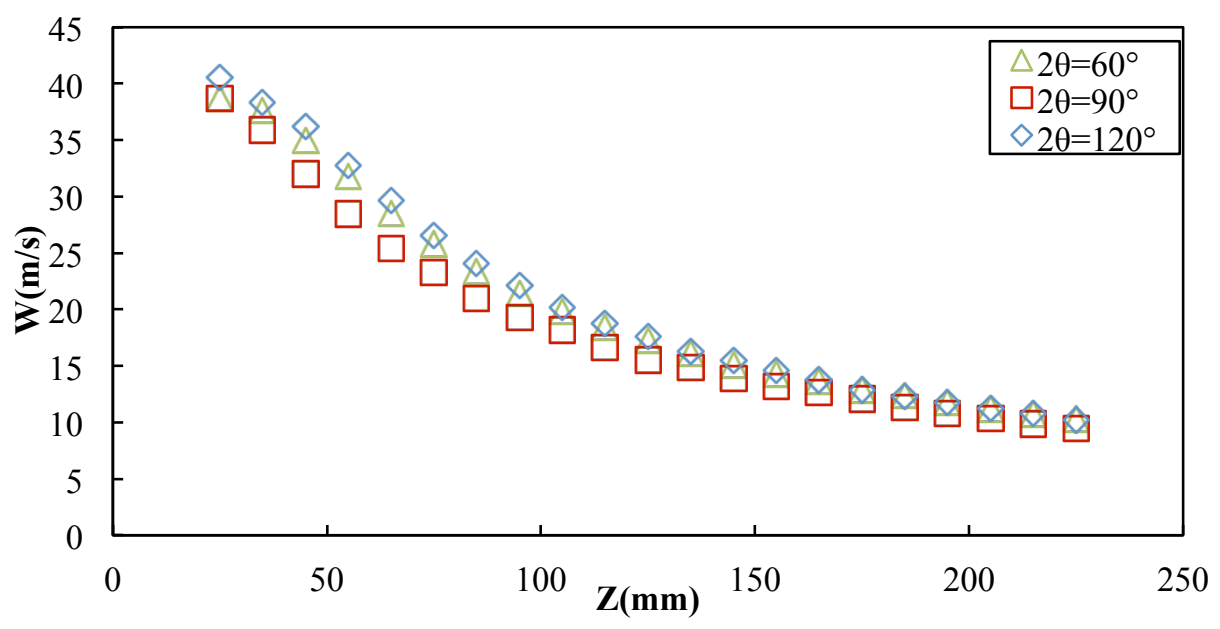

(a) $\mathrm{Q}_{\mathrm{L}}=100 \mathrm{~mL} / \mathrm{min}$

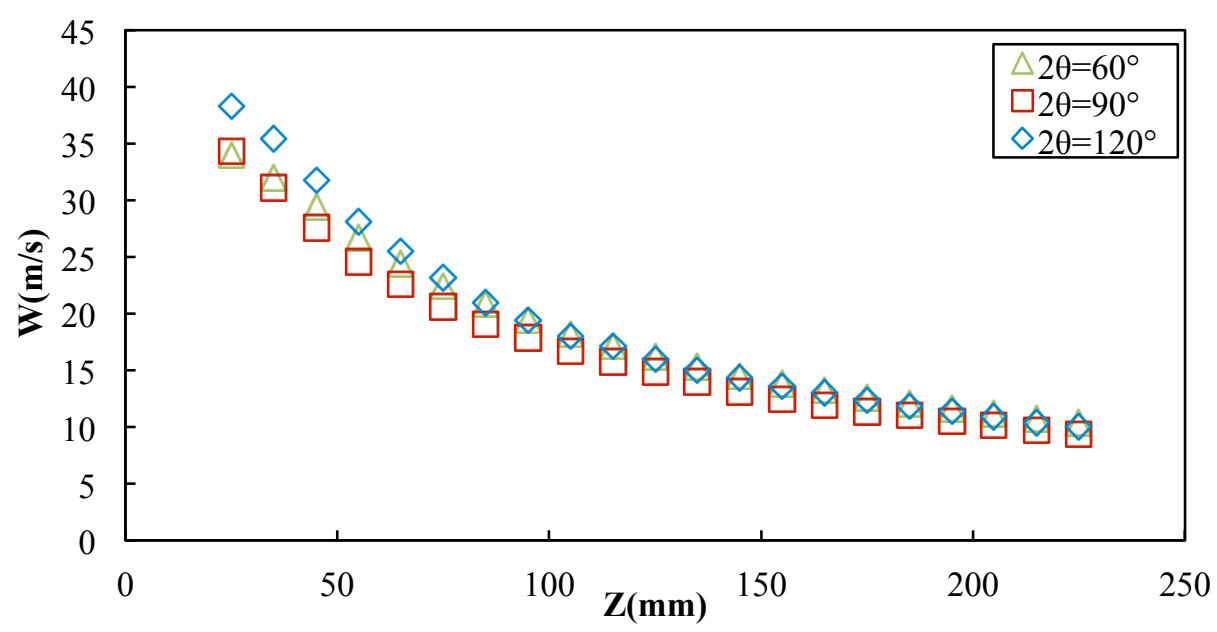

(b) $\mathrm{Q}_{\mathrm{L}}=200 \mathrm{~mL} / \mathrm{min}$

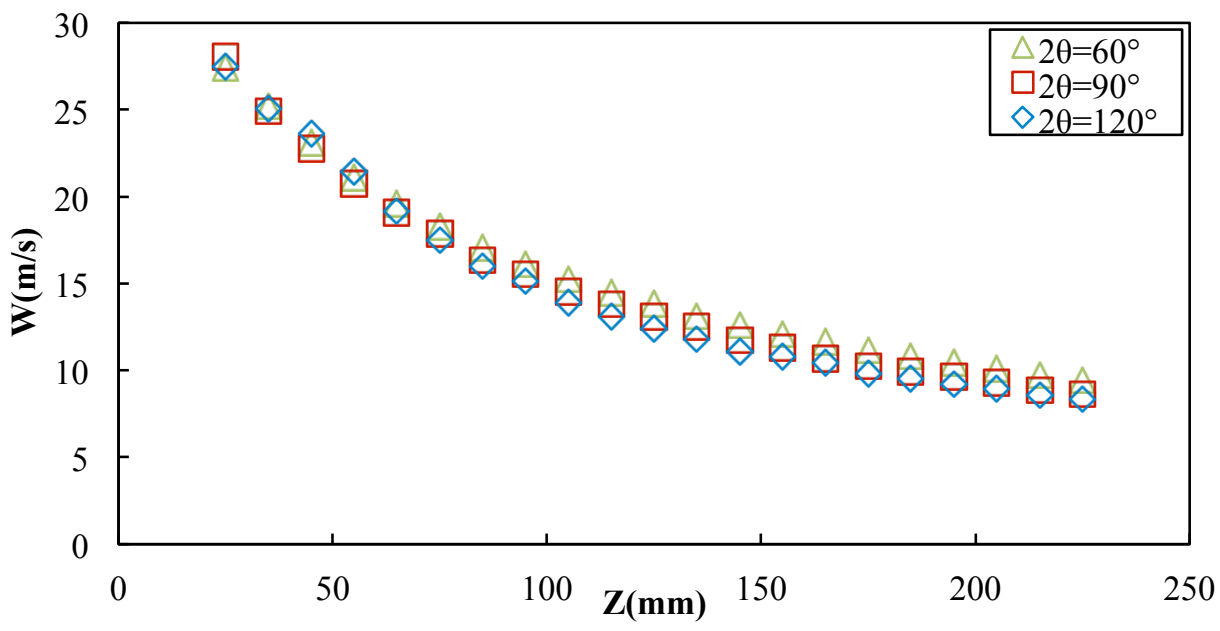

(c) $\mathrm{Q}_{\mathrm{L}}=300 \mathrm{~mL} / \mathrm{min}$

Fig. 13. Mean axial droplet velocity distribution along spray axis at $\mathrm{Q}_{\mathrm{m}}=27.00 \mathrm{~g} / \mathrm{min}$ 


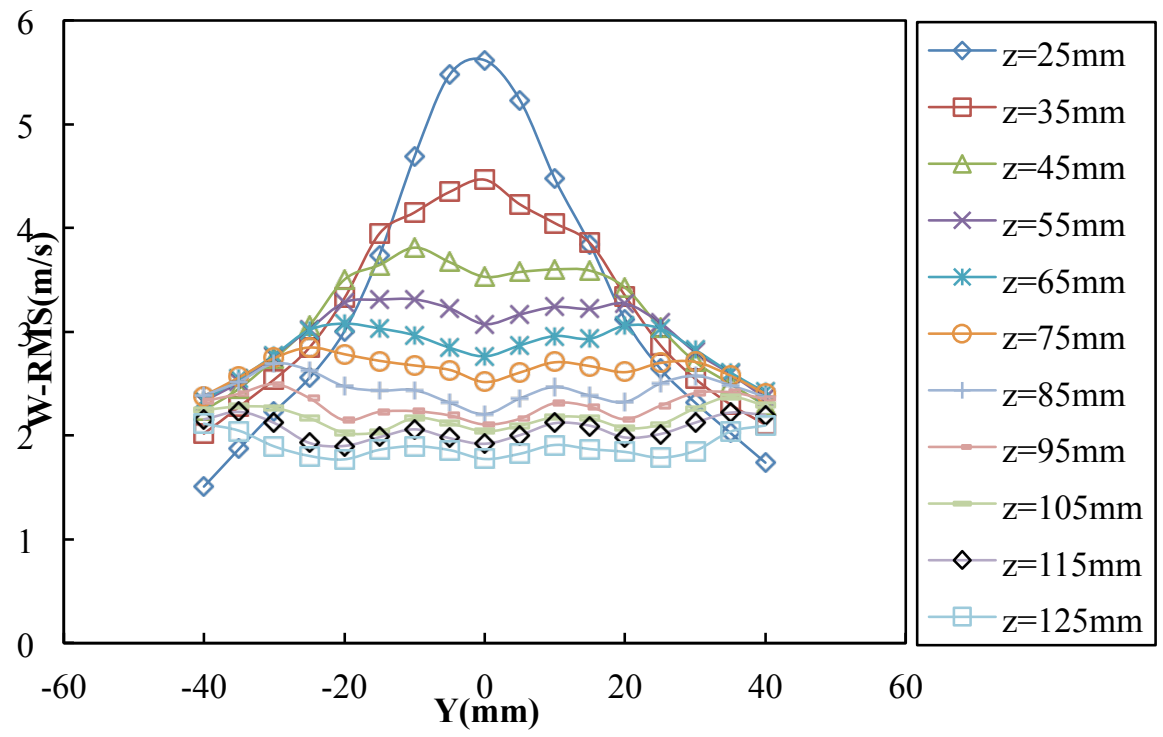

(a)

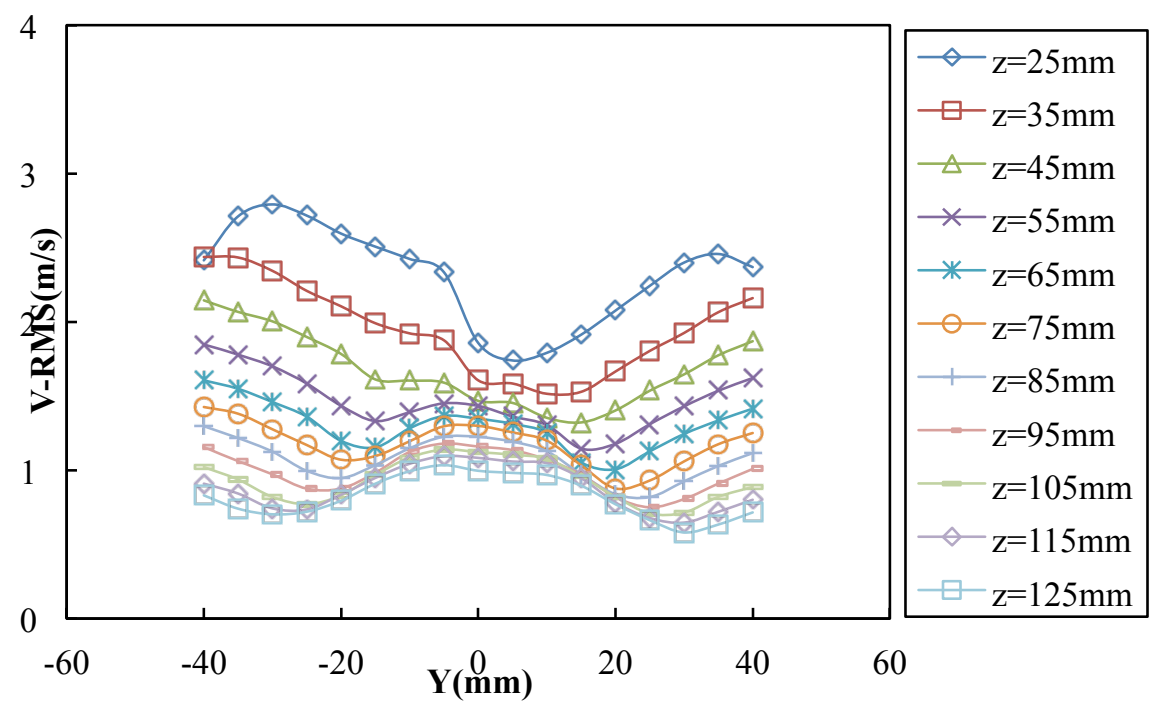

(b)

Fig. 14. Root mean square (RMS) of droplet axial and radial velocity fluctuations at $\mathrm{Q}_{\mathrm{L}}=250$ $\mathrm{mL} / \mathrm{min}, \mathrm{Q}_{\mathrm{m}}=13.50 \mathrm{~g} / \mathrm{min}$ and $2 \theta=90^{\circ}$ 


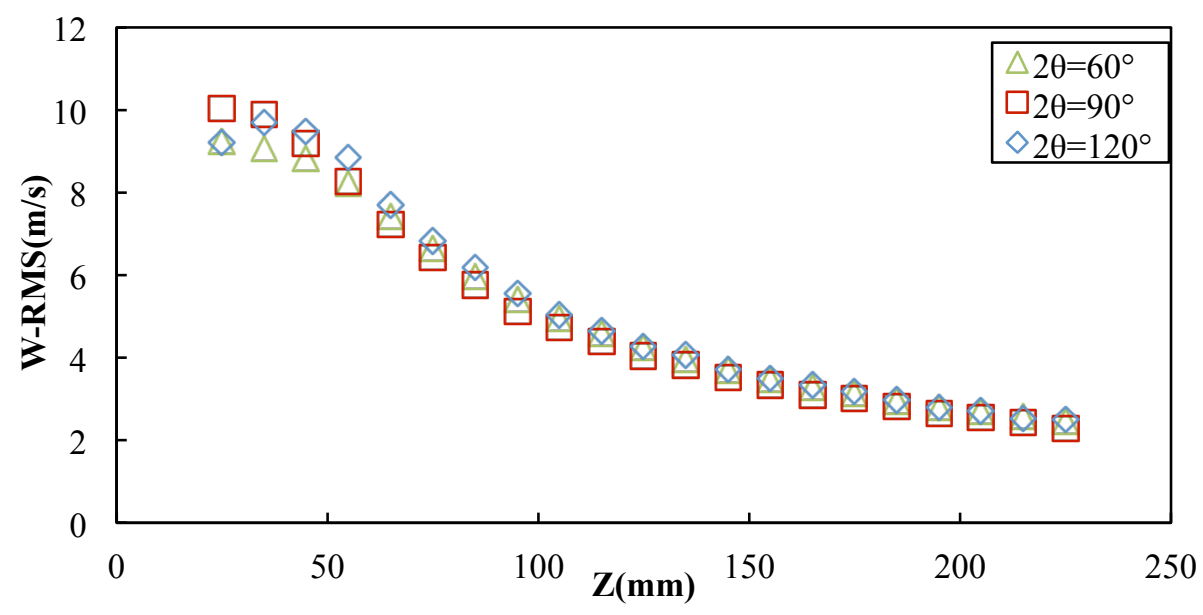

(a) $\mathrm{Q}_{\mathrm{L}}=100 \mathrm{~mL} / \mathrm{min}$

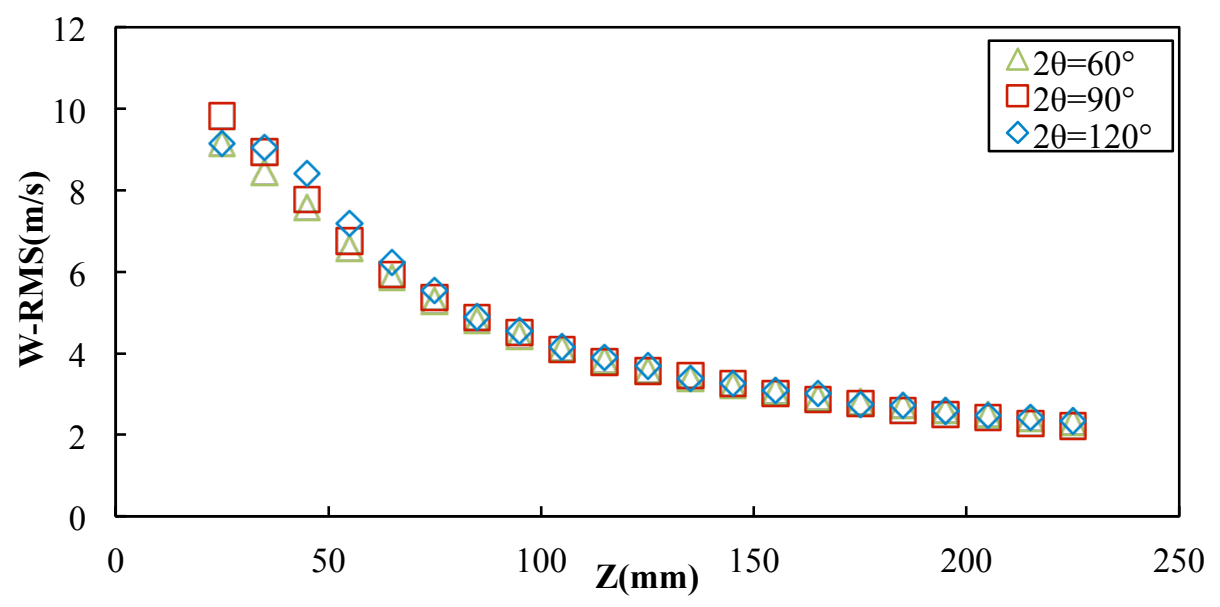

(b) $\mathrm{Q}_{\mathrm{L}}=200 \mathrm{~mL} / \mathrm{min}$

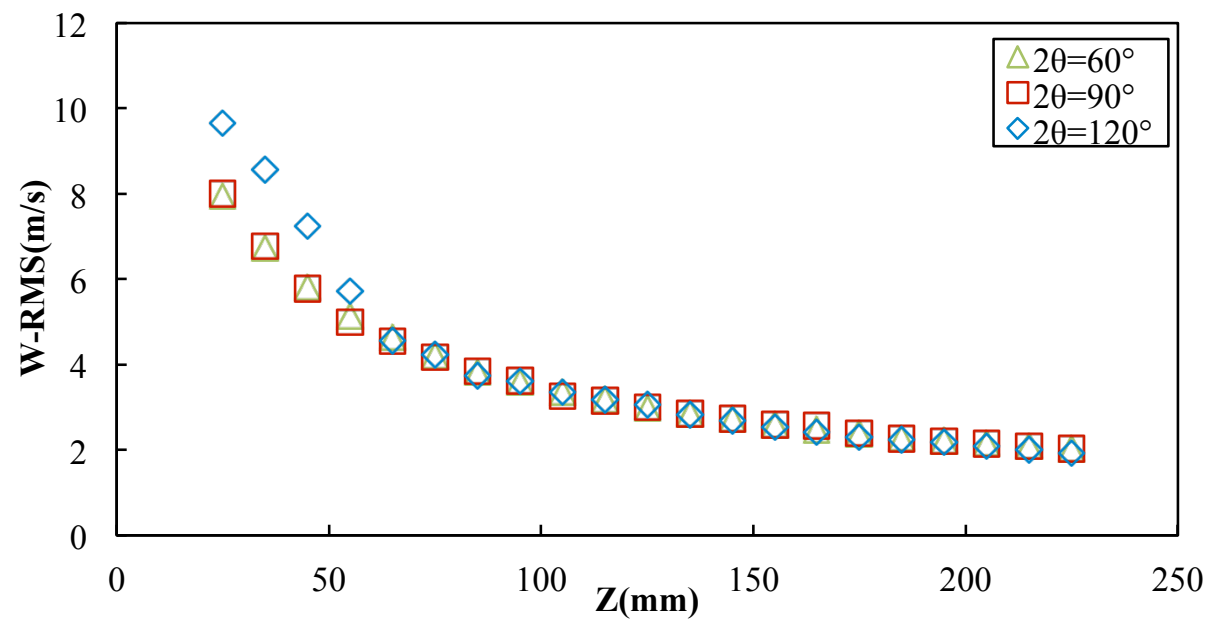

(c) $\mathrm{Q}_{\mathrm{L}}=300 \mathrm{~mL} / \mathrm{min}$

Fig. 15. Root mean square (W-RMS) of droplet axial velocity fluctuations along spray axis at $\mathrm{Q}_{\mathrm{m}}=27.00 \mathrm{~g} / \mathrm{min}$ at impinging angles of $60^{\circ}, 90^{\circ}$ and $120^{\circ}$ 